\title{
EL VOCABULARIO PALMERO DE ANTONINO PESTANA. EDICIÓN DE LA COPIA DE MAX STEFFEN
}

\author{
CARMEN DÍAZ ALAYÓN \\ Universidad de La Laguna / Instituto Universitario \\ de Lingüística «Andrés Bello»
}

\section{Resumen}

La destacada posición en que se encuentran en la actualidad los estudios del español de Canarias es el resultado de una ininterrumpida línea de trabajo que empieza a arraigar a partir de los años cuarenta, cuando el rastreo de los datos y el estudio de los mismos lo comienzan a hacer verdaderos filólogos. Con anterioridad, la situación era bien distinta en lo que se refiere a la cantidad y la calidad de la información y a la enjundia del análisis, pero ello no quiere decir, en modo alguno, que este esfuerzo precedente carezca de valor, extremo que se puede comprobar en las páginas que siguen en las que se centra la atención en una de estas aportaciones iniciales, la de Antonino Pestana Rodríguez, y se acompaña la edición de su Vocabulario palmero, imprescindible para valorar en su justa medida el alcance de su contribución.

Palabras clave: español de Canarias, dialectología, lexicología, lexicografía.

\section{ANTONINO PESTANA AND HIS VOCABULARIO PALMERO. AN EDITION OF MAX STEFFEN'S COPY}

\begin{abstract}
The outstanding position in which the studies on the Spanish spoken in the Canary Islands are at present is the result of an uninterrupted line of research that begins to take root from the forties, when true linguists started to carry out the tracking and study of materials. Before that date, the situation was very different in terms of the quantity and quality of the data and the substance of the analysis, but that does not mean, in any way, that these early contributions have no value, a fact that can be verified in this paper,
\end{abstract}


focused on one of these initial works, that of Antonino Pestana Rodríguez, and that contains the edition of his Vocabulario palmero, essential to have a full notion concerning the extent of this contribution.

Keywords: Canary Spanish, dialectology, lexicology, lexicography.

Entre las iniciativas más tempranas en recoger las particularidades del habla de La Palma, la más noroccidental de las Canarias, se encuentra la del intelectual Antonino Pestana Rodríguez (1859-1938)1. Este hecho, unido al de que su legado tiene una singular relevancia para las investigaciones posteriores, justifica suficientemente un acercamiento a su figura y a su obra, de lo que ya me he ocupado en trabajos anteriores ${ }^{2} \mathrm{y}$, de forma especial, en mi publicación más reciente a este respecto, «En torno al léxico del español de Canarias. Notas sobre el Vocabulario palmero de Antonino Pestana», donde se consideran los principios y criterios que este investigador tiene en cuenta en su proyecto, las características de los materiales que obtiene y los rasgos de las fichas lexicográficas, entre otros aspectos. Ahora mi acercamiento se amplía en estas páginas en las que el Vocabulario palmero se edita por primera vez en su integridad, lo que sin duda va a permitir una más exacta consideración de su naturaleza y de su alcance, sobre todo porque hasta ahora solo ha aparecido citado de forma ocasional o se ha reproducido desmembrado y, en cierta manera, inevitablemente desvirtuado, en el cuerpo frío de algunas recopilaciones lexicográficas del español canario, sin duda necesarias, pero en las que la labor personal y el brillo propio quedan visiblemente apagadas.

Del autor hay que destacar su entrega sincera y generosa a todas aquellas iniciativas o proyectos que tienen que ver con el progreso, el desarrollo del conocimiento y la difusión de la cultura ${ }^{3}$. La historia local va a llamar su atención de modo constante y esto lo lleva a reunir una colección documental de primer orden, con valiosos materiales que van desde

${ }^{1}$ La labor de Pestana se suma a la de sus paisanos Juan B. Lorenzo Rodríguez (18411908) y José Manuel Hernández de las Casas (1864-1937). Véase Pérez García (2009: 211, 242, 324) y Díaz Alayón y Castillo (2013-2014).

2 Díaz Alayón y Castillo (1997:136; 2008: 44-45) y Díaz Alayón (2001; 2003: 553).

${ }^{3}$ Amplios datos en este sentido en Díaz Alayón (2019). 
el periodo de la colonización hasta la primera mitad del siglo XX. La generosidad a la que me he referido, siempre presente en sus gestos y en sus actos, puede verse en el particular protagonismo que tiene en la difusión de la lista de los términos palmeros inventariados por Juan B. Lorenzo Rodríguez, que Pestana se encarga de hacer llegar a Dominik Josef Wölfel y que este incorpora a sus Monumenta Linguae Canariae (Wölfel, 1965: 492). Pero en esta ocasión, como ya se ha adelantado, focalizo mi atención en el interés que muestra por el habla popular y que se refleja en su Vocabulario palmero, donde cataloga materiales que alcanzan las 602 entradas, reunidos a lo largo de muchos años.

La labor de recogida de Pestana debe de producirse en fechas similares a la de los hermanos Luis y Agustín Millares Cubas (1861-1925; 18631935), que constituyen, dentro de los estudios del español de Canarias, el precedente más destacado de la etapa que se abre en los años cuarenta en la que son filólogos de formación y de vocación los que comienzan a llevar a cabo el rastreo y el estudio de los comportamientos lingüísticos insulares. También se acercan los Millares Cubas y Pestana en lo que se refiere a las posiciones generales. En este sentido hay que tener en cuenta que el tratamiento profesional, purista y global que se impone a partir de los años cuarenta en los estudios de las hablas canarias no está presente en los Millares, que parten de otros presupuestos y que señalan en las «Advertencias» iniciales de su obra que aspiran «a tratar el asunto literariamente» y que «no han pretendido realizar obra de ciencia, no por falta de deseos, sino de la preparación filológica e histórica que es indispensable para ello» (s.a.: VI). Esto se confirma en la lectura de la obra, en la que vemos que su interés por el habla, y por el vocabulario en particular, es manifiesto, pero estamos ante una perspectiva de naturaleza parcial, ampliamente centrada en el costumbrismo, que también se ve en los estudios e inventarios lingüísticos de las últimas décadas del siglo XIX y primeras del siguiente, en los que no se da, por lo general, un posicionamiento de índole integral, porque se desecha el habla de los niveles cultos, por supuesta carencia de interés, y solo se tiene en cuenta el de las capas populares, centrándose de forma primordial en las curiosidades y las rarezas, esto es, los vulgarismos, los arcaísmos, los términos de probado carácter local y las expresiones de apreciable sabor rústico. Se trata de unas posiciones que están bastante extendidas en aquellos momentos y que, en grado variable, vemos en otros autores e investigadores, como 
es el caso de Antonino Pestana, que le presta toda la atención al habla de los campesinos y los pastores.

En lo que se refiere a la metodología seguida en la labor de campo, las diferencias entre Pestana y los Millares son más patentes. Estos últimos recogen que sus involuntarios colaboradores fueron la familia, los criados, los amigos y sobre todo los clientes, pero en el caso del investigador palmero resulta evidente, por los resultados obtenidos y por el modo en que estos se presentan, que se produjo un amplio y planeado trabajo de campo y que lo hizo con rigor y dedicación, evidencias que apuntan claramente a un posicionamiento y unos conceptos más exigentes y modernos. Todo esto se advierte de manera particular en el cuidado que Pestana pone en la cumplimentación de la ficha lexicográfica de cada entrada de su Vocabulario, a la que aporta distintos elementos: exhaustividad en la descripción, distinción genérica en los adjetivos, marcas informativas en las expresiones, diversos datos de uso, puntualizaciones de carácter diatópico, y riqueza de ejemplos de uso que precisan el valor del término que trata y donde se ve cómo aprovecha sus conocimientos de la documentación y la literatura oral (Díaz Alayón, 2019).

Como es de esperar, es amplio el conjunto de lusismos que Pestana reúne, sobre todo porque el habla de La Palma es, dentro de las Canarias, una en la que el aporte de portuguesismos es notable. Este es el caso de formas como arganel, bamballo, borboleta, cabaco, cheire, debasar, envoldriar, pingora, pútiga, ratiño, salón, sarabio, suegra, taño, tredo y trópico, entre otros. En este sentido resulta curioso que nuestro autor no maneje referencias portuguesas, pero que sí disponga de datos gallegos, como se puede ver en las entradas bico, buraco y colmo, un hecho que condiciona la adscripción que hace de estas voces. En dibrusarse y manguillir, sin embargo, aporta el criterio de José Franchy y Roca, que los considera portuguesismos. Conviene señalar en este sentido que la breve contribución de Franchy y Roca (1908) constituye la única referencia que Pestana maneja sobre el español insular. No parece conocer los materiales que Elías Zerolo incluye en su contribución de Legajo de varios (1897), ni tampoco maneja las consideraciones en este sentido que hacen Luis y Agustín Millares Cubas en su Léxico de Gran Canaria (1924), al igual que las que recoge M. L. Wagner en su conocida reseña de la obra de los hermanos Millares (1925). 
En relación con los prehispanismos, nuestro autor solamente refleja como tales dos formas: una es gofio, donde aprovecha para corregir a Z. Vélez de Aragón que, en su Diccionario general de la lengua castellana, señala que se trata de un provincialismo cubano; y la otra es time, pero nada dice de la extracción de gambuesa, guanil, mago, perenquén, tenique y velete. Tampoco señala nada con respecto a manteca nula, un registro de especial relevancia porque en esta forma palmera se reúnen a un tiempo la voz española y la prehispánica, que en otras hablas insulares va a perdurar como amolán.

La presencia de americanismos es amplia, sin duda alguna resultado de las intensas relaciones lingüísticas entre Canarias y la América española propiciadas por unas circunstancias históricas, geográficas y económicas específicas y conocidas. Como se sabe, las hablas insulares actúan de vía de entrada de numerosos portuguesismos en el español americano y a ello hay que añadir las unidades que hacen el camino inverso, como ocurre con chinchal, macana, tuno, y tunera. Ello hace que sean numerosas las coincidencias léxicas que se dan entre el español palmero y el americano, especialmente el del Caribe, y Pestana nos aporta distintos ejemplos: chueco 'la persona ligeramente enferma', entrada 'tollina', descarapelar 'quitar o arrancar la epidermis a alguna parte del cuerpo o a la corteza de alguna cosa', jalado 'borracho', lambido 'persona de poca vergüenza', roña 'incomodidad, cólera, inquina', roñoso 'enfadado, incómodo, molesto', tarro 'asta', tareco 'mueble u objeto de poco valor y mérito', traquiado 'entendido, práctico en alguna cosa' y repostada, 'respuesta altanera e insolente'.

Desafortunadamente los muchos méritos de este Vocabulario no han alcanzado un proceso de divulgación acorde con su valor. La obra comenzó a ser más ampliamente conocida a raíz de la encuesta lingüística que Juan Régulo Pérez hace en La Palma en 1945 y en la que accede a la contribución de Pestana, que a partir de entonces aprovechan y citan frecuentemente diversos autores, en especial José Pérez Vidal, Max Steffen y Gerhard Rohlfs. En estos momentos también hay algún proyecto de edición como el de Juan Régulo Pérez, que se refiere, en la Revista de Historia de la Universidad de La Laguna, al catálogo de Pestana, que obra en su poder y del que dice que «una vez debidamente compulsado y anotado, pensamos publicarlo» (1947: 246), pero se trata de una iniciativa 
que, lamentablemente, no se hace realidad y que explica en parte el amplísimo uso que el Prof. Régulo hace de los materiales de Pestana en sus Notas sobre el habla de La Palma. En 1947, partiendo de la copia del Vocabulario palmero en poder de Juan Régulo, Max Steffen elabora una versión mecanografiada que se conserva en la actualidad en la Biblioteca Universitaria de La Laguna, a la que llega en 1974 como parte del legado del Prof. Steffen a esta institución y que es la que manejo para esta edición. Esta copia mecanografiada tiene la particularidad de que no incluye las entradas correspondientes a la letra $F$ e inserta, al final, un «Apéndice de Max Steffen», en el que este investigador señala que, una vez hecha la copia, ha tenido la iniciativa de verificar sobre el terreno todos los materiales recopilados por Pestana, lo que le permitió ver que «el Sr. Pestana Rodríguez trabajó con mucho cuidado y escrupulosidad y que sus referencias son muy de fiar». Además, Steffen reproduce a continuación una breve lista -56 entradas- de variantes y palabras nuevas que salieron a la luz al verificar el Vocabulario.

Todas las circunstancias precedentes, unidas a la naturaleza y la relevancia de los materiales reunidos por Pestana, avalan la presente edición de su Vocabulario palmero. Sobre los criterios que se han seguido para ello, hay que señalar que se parte de los principios fundamentales de respeto a la fuente y de reducir la labor de edición a lo estrictamente necesario. Una lectura detenida de la obra revela que se trata de una aportación en estado avanzado, prácticamente finalizada. Las entradas se encuentran en su mayoría ordenadas alfabéticamente, aunque hay secciones donde esta situación no se da y las expresiones que empiezan por preposición o artículo, al igual que las voces precedidas de este, figuran catalogadas de acuerdo con el elemento inicial. Por eso, teniendo en cuenta estas circunstancias, se ha decidido llevar a cabo una reordenación alfabética. En este sentido, las entradas que comienzan por $c$-incluyen también las que lo hacen por $c h$-, que en Pestana figuran separadamente, y las expresiones o los sintagmas superiores a una unidad aparecen bajo el término más significativo. De igual forma, se ha seguido el criterio de presentar el texto con las peculiaridades de carácter expresivo que contiene el original, por lo que se reproduce avisero, baestilla, barvoleta, belillo, bremeja, cansil, cojer, empregnado, jacer, jallo, jelecho, jormiga, por cima, silantro, sisco, trancaso, velete y zarillo, entre otros 
casos. A ello se añade que, por evidentes motivos de espacio, no se ha procedido a una edición anotada de modo amplio, que acrecentaría sensiblemente las referencias bibliográficas y, con ello, la extensión de la contribución, pero de manera ocasional se incluyen algunas precisiones que se estiman pertinentes, sobre todo para señalar las coincidencias y divergencias con los materiales, cercanos en el tiempo y en el espacio, de Antonio Lemos Smalley, Sebastián de Lugo y, muy especialmente, Juan Bautista Lorenzo Rodríguez y José Manuel Hernández de las Casas ${ }^{4}$.

\section{VOCABULARIO PALMERO \\ por \\ Antonino Pestana Rodríguez}

\section{[A]}

acarrumar. Amontonar; acumular cosas ${ }^{5}$.

achijar. Soltar alguna cosa obligado por la circunstancia o fuerza superior a la voluntad del individuo.

ágamo. En los vegetales, la médula o corazón ${ }^{6}$.

[agua] agua bornia. Agua ligeramente tibia ${ }^{7}$.

aguciosa. Acuciosa.

ajeitado, da. Habilidoso, amañado.

${ }^{4}$ Para Lemos Smalley y Lorenzo Rodríguez se siguen las ediciones de Díaz Alayón y Castillo (2006; 2013-2014). Todas las referencias a Lugo remiten a la edición de Pérez Vidal (1946). Los materiales de Hernández de las Casas (en adelante HdlC) se citan por la copia mecanografiada que elabora Steffen.

${ }^{5} \mathrm{HdlC}$ trae las formas arrumar y arrumbar, y Steffen recoge en Garafía rumba y carrumba 'montón'. En otras hablas insulares se dan ruma 'montón de cosas' y rumacera 'rimero; mucha cantidad, exceso de cosas'.

${ }^{6}$ Lorenzo (41) trae ságamo. Álvarez Rixo usa sámago y samagoso (Voces, s.v. alcaritofe y carozo). Régulo Pérez $(1970: 51,99)$ ve en el ágamo palmero el resultado de la metátesis del portugués âmago 'a medula das plantas; a parte mais íntima de uma coisa ou pessoa; a alma; a essência' (Figueiredo).

${ }^{7}$ Las formas bórneo, bórnea o bornio, bornia se aplican a los líquidos y es uno más de los numerosos lusismos del léxico canario, un hecho que Álvarez Rixo señala en sus Voces. En portugués borno y morno tienen el valor de 'pouco quente; tépido; fig. que não tem energia; sereno; insípido; monótono’ (Figueiredo). 
ajilorio. Gazuza.

ajoriar. Afligir, apresurar, exigir alguna cosa con premura ${ }^{8}$.

ajotas. Mod. adv. Lo mismo que «fiado en», «valido de». Danle también la significación de "¿Por qué causa?», «¿Por qué razón?».

ajoto, ta. Atrevido, temerario.

alarbiar. Desear vivamente comer. Lo usan comúnmente en gerundio con los verbos estar, venir, llegare $i^{9}$.

alboriento. Alboroto.

[alcalde] alcalde de vara. El alcalde presidente del ayuntamiento.

alguero. Sisco que se ha metido en el ojo $^{10}$.

alilayas. Mentira artificiosa.

aljaba. Caja donde llevan el hurón ${ }^{11}$.

[almuerzo] almuerzo mayor. La comida que hacen a las ocho o nueve de la mañana.

alongar. Abalanzar la parte superior del cuerpo hacia delante, ya para ver mejor alguna cosa, ya para alcanzar con la mano cualquier objeto distante. Úsase muy frecuente como reflexivo.

[alma] alma pasada. Alma en pena. déjame el alma quieta. Equivale a «No me molestes», "no me importunes». descargar un alma. Acercarse al lugar donde dicen hay «alma en pena» y oír, después de hacer cruces, santiguarse, etc., lo que aquella desea, con propósito de cumplirlo. No siempre hay que ir a determinado lugar, sino que el alma se aparece en cualquier sitio a la persona que desea hacer un encargo, la cual -si tiene ánimo para ello- la oye, después de hacer cruces en el suelo, tenderse sobre él cubriéndose los ojos, etc.- Es famosa en esta isla la llamada alma de Tacande que cuidaba a los niños de la casa donde habitaba, hablaba con las gentes, grabó una cruz en un arca de madera de tea y, por último, después de haber confesado y hecho varios encargos, desapareció.

altar. Verbo. Construir el segundo piso de una casa.

${ }^{8}$ HdlC trae este valor, pero también el de 'espantar, ahuyentar, oxear', que también incluye Steffen en su apéndice a los materiales de Pestana.

${ }^{9}$ Régulo Pérez (1970: 95, 133) también recoge alarbe ‘tragón, comilón' y alarb(i)ento 'comilón, tragón, especialmente cuando se come mucho con prisa y sin consideración alguna para los demás comensales ni para la forma de comer'.

${ }^{10}$ Es forma muy cercana al portugués argueiro 'palhinha; aresta; coisa insignificante' (Figueiredo).

${ }^{11}$ Igual que el port. aljava 'canudo em que o caçador leva o furão' (Figueiredo). 
altarejo. Sitio elevado de difícil y hasta de peligrosa ascensión.- Aglomeración de trastos que utilizan a veces como escabel.

amasado, da. Lo emplean para denotar el estado de gravedad o postración en que se halla un enfermo. Así dicen: Fulano está muy amasado por Fulano está muy grave.

amodorar. Calcular aproximadamente la cantidad de granos o frutos que puede producir un sembrado, plantío, parra, meda o árbol.

amodornido. Amodorrado.

amurrado. Empurrado.- Mohíno.

amurrarse. Empurrarse.

andancio. Indisposición de salud que se propaga con más o menos rapidez, y que el vulgo suele bautizar con caprichosos nombres, por ejemplo: el topa con todos, el trancaso, la tuberosa, la rosita....

[andar] andar a brucas. Loc. adv. Andar ocupándose de una persona o cosa determinada.- A vueltas.

andén. Pequeña planicie de tierra que se encuentra en los precipicios.

andoriña. Nombre de la cabra de color entero oscuro claro y los cuernos largos y muy abiertos ${ }^{12}$.

ansias. Náuseas ${ }^{13}$.

¿aolo? Equivale a «¿Dónde está?».

apajarado. Tiempo nublado, tristón, en que los pájaros vuelan en grupos y cantan más que de ordinario como presagiando próximas lluvias.

apea. La carga que llevan al frontil.

apear. Atar el costal en la forma apropiada para llevarlo al frontil.

apelajado. Lo usan casi siempre con los adverbios bien o mal para indicar el buen o mal aspecto de las personas, especialmente por el vestido.

apelativo. Apellido.

apelotiar. Apedrear.

apenar. Prohibir la autoridad local entrar en determinados terrenos y lavar en las fuentes en tiempo de sequía: Queda apenada la Fuente de la Yedra. El Monte de las Cuevas Coloradas está apenado.

apolegar. Palpar, tocar con las manos ${ }^{14}$.

\footnotetext{
12 Véase el port. andorinho 'diz-se do gado bovino preto-azeviche' (Figueiredo).

${ }^{13}$ Lemos Smalley (596) trae lancias.

${ }^{14}$ Igual en Lugo. Véanse las formas lusas apolegary apolejar.
} 
apretación. Lo mismo que opresión, y dicen: Tengo una apretación en el pecho, por Tengo una opresión en el pecho.

aquellar. Arreglar o hacer alguna cosa. Lo usan en todos sus tiempos y personas y muchas veces como reflexivo ${ }^{15}$.

ardores. Acedía, indisposición de estómago por haberse agriado la comida.

arganel. Argolla que se coloca en la parte anterior de la trompa de los cerdos para impedir que hocen ${ }^{16}$.

arquitrete. Entrometido.

arrifales. Terrenos áridos e improductivos ${ }^{17}$.

arrimado, da. Amancebado.

atalayar. Concretarse a alguna tarea o trabajo que exija asiduo cuidado y constante atención.

atamar. Concluir, acabar alguna cosa.- Atamando y atamé son formas muy frecuentes ${ }^{18}$.

atarrucar. Llenar apretadamente y con exceso alguna $\cos ^{19}$.

atemar. Insistir. Atema y atemando son formas muy usadas.

atensas. Mod. adv. Lo mismo que ajotas.- Estar atensas es estar a expensas de otro, o de esto o aquello.

atorgado, da. Por gordo, hablando de las personas y especialmente de los niños. Así dicen: Fulano está atorgado por Fulano está gordo. El niño está atorgadito por El niño está gordito.

¿aulo? Lo mismo que ¿aolo?

avisero. La parte del terreno que, por su situación, está menos tiempo bañada por el sol ${ }^{20}$.

[ayunar] ayunar al traspaso. Ayunar sin comer parvedad ni colación, sino la comida del mediodía.

${ }^{15}$ HdlC aporta una definición más precisa: 'verbo para acción indeterminada o para la que no se encuentra nombre apropiado'.

${ }^{16}$ Igual que las formas lusas arganely arganéu.

${ }^{17}$ En las hablas insulares coexisten arrifaly arrife. Amplias referencias en Pérez Vidal (1991: 163-164) y Díaz Alayón (1987: 71-73).

18 Véase el provincialismo azoreano y miñoto atimar 'ultimar', 'levar a cabo' (Figueiredo).

${ }^{19}$ HdlC trae atarugar 'llenar apretadamente o demasiado'.

${ }^{20}$ Para Lorenzo (14-15) es voz prehispánica, pero se trata de un occidentalismo que, en las hablas canarias, es exclusivo de la de La Palma. Véase ALEICan, II, lám. 819; Pérez Vidal (1991: 162-163); Díaz Alayón (1987: 68; 1990: 131); Díaz Alayón y Castillo (2013-2014: 14-15). 


\section{[B]}

bagaña. Glóbulo del ojo.- El ovario que contiene la simiente del lino ${ }^{21}$.

bagañete. El natural de La Banda, en esta Isla:

El bagañete atrevido,

valiente, trabajador,

hombre de lealtad y honor

y de verdad, siempre ha sido.

(«Definición de los palmeros en común y de cada pueblo en particular». Versos anónimos).

baifo. El hijo de la cabra ${ }^{22}$. se te fue el baifo. Expresión familiar que emplean cuando alguno tiene el propósito de conseguir o realizar alguna cosa y se le va, como vulgarmente se dice, de entre las manos ${ }^{23}$.

[bajo] pur bajo. Por debajo, por abajo, por bajo.

balayo. Cereta de paja y corteza de mimbres, de zarzas u otros vegetales.

balsera. La viña que se deja sin cultivo. de balsera. Los viñedos que quedan sin cultivar: Dejé la viña de balsera. En la prov. de Oviedo existe un part. judic. llamado Santa María de Balsera.

balsume. Conjunto de suciedades y aguas cenagosas.

[baluto] de baluto. La heredad que queda sin sembrar: La joya la dejé de baluto. El cercado está de baluto.

bamballo, lla. Indolente, perezoso.- Persona de cuerpo alto y desgarbado ${ }^{24}$.

bambaro. Golpe dado por casualidad y cuya importancia no depende de la agilidad del que lo propina.

banda (La). Territorio que ocupan los ayuntamientos de Los Llanos, El Paso y Tazacorte, y que antiguamente constituyó un solo lugar:

Ya sabrán que Don Francisco

(Dios le conserve en su gracia)

${ }^{21}$ Véase el port. baganha 'casulo que envolve a semente do linho; película que centem qualquer semente' (Figueiredo).

22 Pérez Vidal (Lugo, 1946: 60) señala que parece que esta voz no se usa en La Palma, pero tanto Pestana como HdlC la recogen, e igual hacen Régulo Pérez (1970: 124) y Díaz Alayón (1990: 132). Régulo insiste en este hecho (1947: 253-254) y aporta interesantes materiales. Véase también ALEICan, láms. 395, 396 y 1027; y Wölfel (1965: 491).

${ }^{23}$ Igual valor en los Millares Cubas, pero también para otros autores esta expresión equivale a «que se ha olvidado alguna cosa que se iba a hablar o hacer» (Álvarez Rixo, 1992, s.v. bayfo; Alvar, 1959: 131).

${ }^{24}$ Lugo trae el valor de 'despilfarrado'. 
salió de aquesta ciudad

para el lugar de La Banda.

(Romance dedicado a D. Francisco Ríos, con motivo de un viaje que hizo a La Banda. Autor desconocido).

barbaluta. Los primeros hilos que tiende el gusano de seda para en su centro formar el capullo.

barbiar. La forma o manera que tiene cada individuo de usar la barba. Así dicen: Fulano tiene o usa un barbiar muy feo.

barbusana. La cabra que tiene blanco el pelo y el del hocico rayado de negro.

barrosa. La cabra que tiene el pelo de color amarillo anaranjado.

barvoleta, barvuleta. Mariposa ${ }^{25}$.

bascullo. Acumulación de basuras y desperdicios.

basurda. La lana de las cabras y ovejas antes de lavada.

batiquiar. Sacudir con violencia y repetidamente a una persona, animal o cosa. Zambullir o remojar en el agua a alguna persona o animal.

batuallo. El caldo que contiene residuos de cocido. Lo dicen a veces por el mismo cocido.

bayita. La cabra que tiene el color del pelo de los cuartos delanteros negro y el resto del cuerpo de color veige muy claro.

bebentina. Bebida.

belillo. Lío o envoltorio. Se aplica este nombre especialmente cuando el lío se envía de un lugar a otro ${ }^{26}$.

berenguela. Persona muy delgada.

bicácaro. Cierta clase de tomate pequeño.- Planta indígena de Canarias, que según el sabio José Viera y Clavijo en su Dicc., da un fruto que es "por dentro blanco, pulposo, jugoso y lleno de muchas semillitas menudas, ovales y lisas», añadiendo que fue el «fruto silvestre más delicioso que tuvieron y apreciaron en mucho los habitantes primitivos de nuestras islas».- Hablando de las personas, llaman también bicácaros a los ojos irritados, enfermos ${ }^{27}$.

bico. Pico o punta.- Contracción de la boca o cara que hacen los niños antes de llorar mimosamente. Es voz gallega.

${ }^{25}$ HdlC trae borboleta y aporta precisiones de significado.

${ }^{26}$ Las fuentes más tempranas registran belillo, pero debe ser velillo. Curiosamente HdlC trae belillo 'pequeño atado con cosas' y velillo 'persona bruta'.

${ }^{27}$ Lorenzo (23). Régulo Pérez (1970: 124) anota también que del que tiene los ojos estropeados, con una nube, tracoma, etc., se dice que tiene los ojos bicácaros. También se usa huevo bicácaro, huevo podrido (Díaz Alayón, 1990: 138). 

Miña nai como e tan pobre
e non ten pan que me dar
éncheme a cara de bicos
e despois rompe a chorar.
(Copla gallega)

bimba. Bebida. Así dicen: En el bautizo, boda, etc., hubo bimba.

bimbarse. Caerse de alguna altura.

biquera. Pequeña canal por la cual pasa el mosto desde el lagar a la lagareta.Prolongación de la quesera en forma de canal, por donde se desaloja el suero que el queso va depositando en aquélla.- Techo, paraguas, sombrero, etc., que por mal estado o por exceso de agua que recibe no puede impedir que ésta se filtre por ellos.

bocarón. Agujero.

bolla. Torta pequeña.

[bollo] bollo de jelecho. Torta hecha con la harina de la raíz del helecho mezclada con la de centeno o acemites y cocido al tostador. Nuestros campesinos hacían gran consumo de estas tortas antiguamente, cuando el comercio era desconocido en los pueblos; hoy sólo lo comen en los años muy escasos. bollo estreme. Torta hecha con la harina de la raíz del helecho, sin mezcla de ninguna otra ${ }^{28}$.

boquetas. Muecas hechas con la boca.

boraco, ca. Lo mismo que buraco.

borrallo. Borrajo.

borsolana. Aljofaina.

bostaco. El excremento que un animal o persona arroja de una sola vez.

botarse. Acometer. «...la demandada se le tiró y la tumbó al suelo y le dió con los pies y las rodillas en la boca del estómago y con una piedra le dió en la frente a cuyo acto fueron apartadas por Don José Sánchez pero la demandada se le bolbió a botar y bolvió a darle». (Juicio de faltas promovido por Doña M.R. contra Doña J.G.L. en Mazo, el 30 de abril de 1857).

bremeja. La cabra que tiene el color del pelo rojo oscuro.

${ }^{28}$ También Lemos Smalley trae bollo estreme: «y en los pobres el pan que hacen con harina de la raiz del helecho, que caban, pican, secan y muelen, lo que suelen mezclar con salvado ó afrechos de trigo, haciendo panes negros y correosos, pero de buen sabor; y los muy pobres nada le mezclan, y lo llaman bollo estreme...» (Díaz Alayón y Castillo, 2006). En sus Voces, también Álvarez Rixo recoge bollo estreme o estremie 'el pan de helecho sin liga de afrecho ni otra cosa'. 
brequiar. Pescar con baestilla.

broca. La res vacuna que tiene la cornamenta hacia delante e inclinada al suelo.

brocha. Tira de cuero que en la canga va de un cancil al otro por bajo el pescuezo del animal.

[bruma] bruma rastrera. Niebla.

buchi. Voz con que llaman a los perros.

[buey] a bebe buey. Modo adv. Beber seguidamente y sin descansar alguna cantidad de líquido por la misma vasija que lo contiene; y cuando el líquido es caliente en un grado de temperatura que se puede beber en la forma dicha. ijachi buey! Voz con que animan a los bueyes para que aceleren su marcha.

bufete. Gaveta de las mesas.

buraco, ca. Agujero estrecho y más o menos profundo que se encuentra en los riscos. Es voz gallega:

O dia que ti naciche

caeu do ceo un anaco,

o dia que ti te morras

taparán ese buraco.

(Copla gallega)

burro. Pieza de madera que introducida en una cavidad que al efecto tiene el órgano de los telares hace oficio de palanca para hacerlos girar al liar la urdimbre.- Soporte.

buti. Voz con que llaman a los perros.

[C]

cabaco. Trozo o astilla de madera ${ }^{29}$.

[cabales] no estar en sus cabales. No estar en completo juicio.

[caballeras] a las caballeras. Mod. adv. Manera de cargar una persona a otra llevándola a horcajadas sobre los hombros.- $A$ las caballotas dicen en la ciudad de El Paso y en Tazacorte.

${ }^{29}$ En las hablas canarias se dan los valores de 'trozo menudo de leña', 'astillas que se producen al cortar madera', 'astilla seca y pequeña para encender la lumbre', y 'pedazos pequeños de una vasija de barro, loza o cristal que cae y se rompe'. Asimismo, es frecuente la expresión estar flaco como un cavaco 'estar muy delgado'. Se trata de otro occidentalismo ibérico. En portugués, cavaca 'acha, pedaço de lenha' y cavaco 'estilha, pequena lasca de madeira; pedacinho de madeira, para lenha' (Figueiredo). 
cabañuelas. Ciertas señales que observan en la temperatura o estado del tiempo en determinadas épocas del año y por la cuales infieren las condiciones buenas o malas del mismo año y cuáles serán los vientos reinantes y meses en que probablemente habrá lluvias o sequías. Así dicen: Estos chubascos o estas calores son las cabañuelas de tal o cual santo, p. e., San Miguel, San Mateo, la Virgen de Agosto o Septiembre, etc.

cabaquiar. Arrancar trozos a la madera o leña.

caboco. Precipicio más pequeño que el llamado caldero ${ }^{30}$.

cabrillas. Dos piezas de madera que se colocan horizontal y paralelamente sobre los tablones que cubren el queso o pie en los lagares.

cabuco. Por equívoco. En esta cuenta hay cabuco. Está usted cabucado.

cachariz. Cariz. Lo dicen también refiriéndose al buen o mal aspecto del rostro. cachazas. Mandíbulas.

cachebuche. Baratija.

cachibuche. Baratija.

cachimbero. El que hace cachimbas.

cachimbiar. Fumar por cachimba.

cacho. Fusil. cargar el cacho. Exp. fam. que equivale a «entrar de soldado». cachos de era. Residuos de la trilla que emplean en la alimentación de animales domésticos.

cachofa. Ovario de algunas plantas.- Bulbo de otras.- Parte anterior del tubo de la regadera.

cachola. Cárcel. encacholar, «meter en cachola» ${ }^{31}$.

cachopa. Lo mismo que cachofa.

cachorra. Sombrero flexible de ala ancha.

caco. Trozo de loza ${ }^{32}$.

cafora. La res vacuna que tiene el pelo de la cabeza y el hocico de color negro.

${ }^{30}$ HdlC, s.v.; y Lorenzo (42). En La Palma caboco se ha recogido como 'brusco desnivel o salto en algunos barrancos en el que la erosión ha excavado una media caña vertical $u$ otra suerte de oquedad'; 'surco ancho y profundo formado a lo largo de un camino de tierra por el arrastre de maderas, por las aguas de lluvia u otros agentes'; 'concavidad del terreno'; 'foso'; e 'infierno del molino'. En algunas zonas, como en Puntallana y San Andrés y Sauces, se produce la alternancia caboco /taboco. Véase Pérez Vidal (1991: 164-165, 258) y Díaz Alayón (1987: 84).

${ }^{31}$ HdlC trae cachola 'casquivano'; 'cabeza'; 'cárcel o corrección', y encacholado 'preso'.

${ }^{32}$ En portugués, caco 'pedaço de loiça, vidro, etc.' (Figueiredo). Véase Pérez Vidal (1991: 142) y Régulo Pérez (1970: 138). 
calacería. Holgazanería ${ }^{33}$.

calasero, ra. Holgazán. «...por lo que mira a plantíos pudiera haber mucho más adelantamiento assí en viñas como en árboles frutales respecto a que tienen muchos valdíos en donde poder trabajar y por calaseros no lo hacen...». (Carta de D. Diego José de Vargas Machuca a D. José Feyjoo, fechada en Tijarafe a 9 de septiembre de 1778, y que obra original en la información promovida por la Real Sociedad de Amigos del País, acerca del cumplimiento de un despacho del Alcalde Mayor de la isla dando reglas para el pastoreo del ganado).

caldero. Hondos precipicios que hay en los barrancos, generalmente en sus cauces, cortados perpendicularmente y en forma semicircular.

[callada] a las calladas. Mod. adv. En silencio, sin ruido.

[calzón] calzón corto. Especie de zaragüelles que usaban los campesinos de Canarias y que aún llevan hoy en algún pueblo del archipiélago.

camada. Las porciones de cosas que están extendidas unas sobre otras. De las frutas secas se dice que son de una misma camada aquellas que se han llevado al tendal o pasaron en la misma fecha.

campana. Deuda: En la tienda de Don Fulano hice una campana. Tengo una campana con Don Mengano.

campina. Chaparrón.

campista. La persona que está dedicada exclusivamente a las faenas del campo.

canaleto. Ciertos sitios, hondos y estrechos, que afectan la forma de canal.

candilejo. Trípode tosco de madera, con un trozo de hojalata en forma de canal en su parte superior, en la cual colocan las teas encendidas con que se alumbran.

candonga. Cárcel.

caneco. Objeto casi inservible y de poco valor.

${ }^{33}$ Véase ALEICan, II, lám. 723, que registra la forma con el sentido de 'modorra, gandulencia, pereza' en la localidad de Mogán. Véanse las formas lusas calaça 'preguiça; homem preguiçoso, calaceiro', calaçaria 'qualidade ou vida de calaceiro; ociosidade', calacear'mandriar; viver na ociosidade, ou à custa de outrem' y calaceiro 'mandrião, vadio' (Figueiredo). 
cangallo, lla. Persona o cosa vieja ${ }^{34}$. de cangallas. La persona que está holgando, tendida de espaldas ${ }^{35}$.

cansil. Pieza de madera de un pie de largo y tres centímetros de ancho que se introduce en la canga, de los cuales queda uno por cada lado del pescuezo del buey, y que unidos cada dos entre sí por una correa que llaman brocha dejan a los bueyes uncidos a la canga.

carapela. Epidermis. Corteza.

caraportal. Los costeros designan con este nombre la pesca de congrio, casón y morena que hacen para sí en las horas que les quedan libres de sus obligaciones, y también los buches y lenguas de los demás pescados.

cardosa. Nombre que dan a la cabra de pelo blanco y negro entremezclado y patas negras.

carranca. Gesto o ademán colérico ${ }^{36}$.

carruca. Nudo o lazada que se forma en el hilo al devanarlo o al coser.

[casa] casa de despojo. La casa o casas inmediatas a la que sirve de habitación y que están destinadas a graneros, establos o pajares. El Nomenclátor Oficial de Canarias, del año 1887, llama a tales edificios casas de despojo. casa de los botones. La advertura que se hace en las prendas de vestir para entrar los botones y abrocharlas. casa terrera. Casa de un solo piso.

cascarrillas. Las suciedades adheridas al cuerpo, secas y en forma escamosa. Lo dicen más especialmente por las de los ojos y la nariz.

castaña. Golpe dado con el puño en el rostro.

[cata] echar cata. Modismo que significa fijar la atención, percatarse, etc.

cerar. Lo mismo que cernar.

cerce. Adv. mod. A cercén, a raíz.

${ }^{34}$ Es muy frecuente oír la expresión flaco como un cangallo. En portugués, cangalho, fam. 'pessoa ou coisa inútil ou velha. Traste velho e inútil' y cangalhão 'homem precocemente avelhentado' (Figueiredo). Bluteau recoge cangalho como 'animal velho, inútil, e assim dos homens'.

${ }^{35}$ Pérez Vidal anota que en Tenerife y La Palma caer de cangalla o cangallas es 'caer para atrás, especialmente cuando por efecto del impulso de la caída se levantan las piernas (Lugo, 1946: 79). Véase la loc. adv. lusa de cangalhas 'de pernas para o ar, estateladamente' (Figueiredo).

${ }^{36}$ Véase el portugués carranca 'rosto sombrio, carregado; aspecto que indica mau humor; cara feia; maus modos; cara disforme, de pedra, madeira ou metal, com que se adornava diferentes construções' (Figueiredo). 
cernar. Hacer un corte circular en los troncos de los árboles, quitándoles la corteza, para que el derrame de la savia ocasione la pérdida de los vegetales ${ }^{37}$. cerodio, a. Zerrollo. Todo lo que por efecto del calor del aire va perdiendo la humedad y está próximo a secarse ${ }^{38}$.

cerrudo, da. La persona de aspecto demasiado severo y rígido.

chafallo. Cosa vieja y despreciable ${ }^{39}$.

chamizal. Terreno improductivo.

chanco. Zapato viejo.- Persona baja y despreciable.

charamezo. Leña delgada y seca. Charamusco dicen en la villa de El Paso ${ }^{40}$.

chascar. Comer torrado.

chavernoso, sa. Persona de poco apetito y a quien desagradan la mayor parte de los alimentos ${ }^{41}$.

cheire. Niebla espesa y baja acompañada de lluvia menuda.- El mal olor que exhala alguna persona, sitio u objeto ${ }^{42}$.

chepe, chepa, chepas. José, Josefa.

chicharrero. Pescador de chicharros.

chilrar. Chillar.

chilrido. Chillido.

chilrón. Chillón.

chincar. Comer torrado.

chinchal. Ventorrillo.

chiquirriño. Persona o cosa demasiado pequeña.

chistete. Remoquete.

\footnotetext{
${ }^{37}$ Pestana también trae sarnar, al igual que Steffen en su apéndice. En portugués, cernar.

${ }^{38}$ Coexisten en el habla de La Palma la forma española cerollo y la lusa serodio. Véase Pérez Vidal (1991: 207).

${ }^{39}$ Véase Hernández de las Casas, s.v. chafallo y trafallo y Pérez Vidal (1991: 143).

${ }^{40}$ Lorenzo (25).

${ }^{41}$ En otras fuentes, chaberoso. Véase el apéndice de Steffen a los materiales de Pestana y Régulo Pérez (1970: 88).

42 Véase Pérez Vidal (1991: 154); Régulo Pérez (1970: 40, 103); y Díaz Alayón (1990: 135). En sus Voces, Álvarez Rixo nos dice que cheo es «Voz derivada del portugués cheiro, olor. La he oído en el pueblo del Realejo, pero para significar tufo desagradable del vino. En la isla de La Palma tiene mucho uso».
} 
chucallero, ra. Chismoso ${ }^{43}$.

chueco, ca. La persona ligeramente enferma.- La gallina cuando está clueca.Podrido, corrompido.

chumbo. Lo mismo que cheire en la primera acepción.

chupadero. Fuente que produce poca cantidad de agua.

chupano. Casucha de poca importancia.

churmisgar. Lloriquear.

[churrero] churrero del sol. Sitio o paraje donde haya bastante sol: Estoy al churrero del sol.

churume. Olor fétido.- El líquido que arroja de sí algún cuerpo.

churumijar. Lloriquear.

chuti. Voz para ahuyentar a los perros: ;Chuti, fuera!

[cirro] jacer cirro. Arrugar el entrecejo.

ciscallo. Pequeños residuos de maderas, telas, etc.

cisco. Pequeñísimos fragmentos de alguna cosa.- Estiércol.

Por plantar, la dura laja

valientes quiebran en ciscos

(«Definición de los palmeros en común y de cada pueblo en particular», de autor anónimo).

claca. La bellota del mar.

clarea. En los días lluviosos el momento en que escampa o cesa de llover.- Clarea del pastor, la que generalmente sobreviene cerca del anochecer.

claricias. Noticias vagas.

clavellina. La res vacuna de pelo colorado.

cochi. Voz que emplean para llamar a los cerdos.

cochinillera. Jornalera dedicada a la recolección de la cochinilla.

cocho, cha. Completamente lleno. Se dice principalmente de un furúnculo o nacido que está enteramente lleno de pus.

codia. La corteza del pan.

coladera. Pequeño depósito inmediato a los aljibes, construidos con objeto de que las aguas llovedizas, al pasar por ellos, dejen en su fondo parte de la

${ }^{43}$ Lugo, s.v. chocallero. Véase el port. chocalheiro 'mexeriqueiro, que revela indiscretamente o que ouviu; aquele que fala muito e indiscretamente' (Figueiredo). 
tierra y otras materias que arrastran en su curso, entrando más limpias en los aljibes.

colmar. Cubrir con paja de centeno los techos de las habitaciones.

colmero. El haz de paja de centeno.

colmo. Paja de centeno.- Techo de paja.- En Galicia llaman también colmo a los techos de paja.

combanido. Lo que está maleado, putrefacto ${ }^{44}$.

comechoso. Económico; el que todo lo aprovecha o utiliza.

comestina. Comezón.

comparancia. Comparación.

concha. Fruto de la tunera que madura fuera de tiempo y por lo general desmedrado.

conduermas. Morosidad, aplazamiento en la ejecución de alguna cosa.

conduto. Entre los campesinos, cualquier vianda con que acompañan al gofio, el pan o las patatas ${ }^{45}$.

coneja. Nombre que dan a la cabra que es de color pardo, parecido al del conejo salvaje, y los cuernos caídos sobre las orejas.

[conejo] a tira conejo. Mod. adv. Forma de llevar la correa o soga, que envuelven alrededor del cuerpo, transversalmente del hombre derecho al costado izquierdo.

coralera. La cabra que tiene el pelo de color rojizo.

corales. Nombre que dan a las cabras de pelo colorado rojizo, orejas con pelo blanco y colorado o blanco y negro entremezclado.

cordero. Nombre que dan al buey manso, de pelo colorado ${ }^{46}$.

correa. Tira delgada de cuero de cabra con que cosen la suela cruda en el calzado de este nombre. Previamente la remojan a fin de estirarla y redondearla para que quede fina y redonda como un hilo. Después de seca la emplean. Los primitivos palmenses cosían sus vestidos con correas y nervios de animales

${ }^{44}$ HdlC, s.v. combanido y combanir. Se trata de otro lusismo del habla insular. En portugués, combaniro combalir 'abalar; tornar fraco, abatido; deteriorar, tornar podre', y combalido 'deteriorado, podre (especialmente falando-se de fruta); abatido, adoentado, fraco' (Figueiredo).

${ }^{45}$ Lemos Smalley refleja esta forma: «...á lo que suelen agregarles mojos de mucha pimienta, ó alguna otra cosa que llaman conduto, y viene á ser pescado seco, fruta pasada \&.» (Díaz Alayón y Castillo, 2006). Otras referencias en Hernández de las Casas, s.v. condutary conduto; Régulo Pérez (1970: 140); y Pérez Vidal (1991: 149-150).

${ }^{46}$ HdlC trae cordero como 'buey oscuro'. 
corredera. El zaguán, hablando de las casas.- Desagüe que tienen algunas casas de campo por la parte trasera de las mismas.

corrial. La piel de cabra preparada para hacer correas con que cosen la suela del calzado. Esta preparación consiste en clavar la piel cuando aún está fresca, de modo que quede bastante tensa, hasta que se seque; ya seca, la dividen en delgadas tiras.

corrimansas. Diarreas.

corruto. Lo que es conocido; del dominio público. Así dicen: Eso está corruto, que equivale a «Eso es público».

corza. Especie de narria o rastra ${ }^{47}$.

cospe. Trozo grande de madera blanca que, al elaborar los pinos, desprende de la tea.

costero. El barco destinado a la pesca y salazón en la vecina costa de África.- El tripulante de estas embarcaciones.- Cierta clase de pájaros.

cuantinomás. Cantidad pequeñísima.

cucharear. Llevar a los jóvenes a las fiestas, bailes, etc., con el objeto de que encuentren novio.

cuéscaro. Áspero, reseco.

curiñas. En los lagares, unas piezas de madera que están colocadas perpendicular y paralelamente de dos en dos a los extremos de aquél. Entre las dos curiñas de un lado va afianzada la viga por medio de un pasador y por entre las del otro extremo pasa dicha viga, descansando sobre la templa.

[D]

dañado. Lázaro; enfermo de elefantiasis.

debasar. Destrozar las personas o animales las siembras o $\operatorname{arbolados}^{48}$. dar a debase: autorizar para que entren en el terreno a debasar. entrar a debase: introducirse en un terreno con el propósito de debasar. «...que de tres ó quatro años á esta parte pospuesto el temor de Dios y en grabe daño de su conciencia y en perjuicio mío, y sin temor ni respeto a la justicia que Vmd. administra me han estado dañando y debasando dicha propiedad». (Escrito

${ }^{47}$ Véase Pérez Vidal (1991: 266-267); Régulo Pérez (1970: 103); y Díaz Alayón (1987: 8990). En Madeira, corça tiene el valor de 'tábua puxada por bois e utilizada para transporte de mercadoiras' y en Tras-os- Montes el de 'zorra rudimentar, grosseira, para transporte de cantaria' (Figueiredo). La voz existe también en algunos territorios del occidente ibérico limítrofes con el luso.

${ }^{48}$ Véase las formas lusas devassary devasso. 
de D. Nicolás Abreu, denunciando por daños a P. de los A., vecino de Velhoco. Año 1758).

[decir] no le digo. Expresión que equivale a «Lo ignoro»; «No lo sé»; p. e.: ¿Dónde vive Fulano? - No le digo.

deque. Deme.

derriscado, da. Despeñado.

desafuriado. Desaforado.

desajeitado, da. Desmañado.

desajornillar. Cortar las ramas del arbolado que sombrea un terreno.

desarmentar. Retirar del terreno los sarmientos que se han cortado a las viñas.

desbrocinarse. Ponerse de bruces.

descarapelar. Quitar o arrancar la epidermis a alguna parte del cuerpo o a la corteza a alguna cosa.

desconchado. Con luxación.

desconchavado, da. Desgobernado.

desconchavo. Luxación.- Desorden, falta de gobierno.

descospar. Separar con el hacha la madera blanca de la tea, en los pinos apeados.

desguarniado, da. Contrahecho, desbaratado.

desmantelado. Desmejorado, flaco, flojo.

desmorecerse. Reírse o llorar con tal exceso que casi se pierde el sentido y la respiración.

desmorecido. Part. de desmorecerse.

desorillo. Cierta faja de monte que dejan en los terrenos al roturarlos, con el propósito de cortarlo más tarde y quemar las ramas para que las cenizas les sirvan de abono.

desvero. Lo mismo que desorillo.

diares. Diablo.

dibrusarse. Lo mismo que desbrosinarse. Don José Franchy y Roca, en un artículo titulado «Cómo se habla en Canarias», dice que la palabra dibrusarse procede del idioma portugués. Véase el núm. 760 del periódico madrileño Las Canarias, correspondiente al jueves 7 de mayo de 1908.

[domingo] domingo llano. Los segundos y cuartos domingos de los meses, que no coinciden con ninguna festividad, sin duda porque consideran más solemnes los primeros y terceros domingos, por estar consagrados a la Virgen y al Señor, respectivamente. 
[E]

ea. Interj. con la cual llaman a las cabras repitiéndola varias veces.

eja. Voz con que ahuyentan a las cabras haciéndolas variar de sitio.

embarrar. Tropezar con algún estorbo que impide el avance de alguna persona o cosa.

embate. Percepción repentina de algún olor fuerte.

embozada. Almorzada.

embrujar. Envolver de cualquier modo y sin cuidado ni orden.- Cubrir liando en abrigo, manta, etc., a alguna persona.- Enredar ovillos, madejas u otra cosa semejante.

empantanado. Parado, lelo, pasmado.

empanturrarse. Comer de algún manjar hasta el extremo que sólo su vista causa repugnancia.- Úsase también como activo.

empurrar. Embarrar.

empurrarse. Ponerse cabizbajo y triste, u ocultar con disgusto o enfado la cara evitando mirar o hablar a los demás.

encabusiar. Echar de algún lugar a una persona o animal.

encachazado, da. La prenda de ropa en la cual se ha empregnado la suciedad de tal modo, que a pesar del lavado no vuelve a su primitivo color. Los campesinos dicen encachizado.

encerar. En los incendios de los montes, cortar árboles y arbustos en una larga faja, a fin de aislar el fuego evitando su propagación.

encetar. Destapar una botella, garrafón, tonel, etc., y principiar a gastar su contenido; lo mismo una tela, caja, etc., que contenga algo ${ }^{49}$.

enchumbar. Mojarse mucho.

enclente. Mirar con fijeza a una persona u objeto.

encontinas. Deseo o tentación de hacer alguna cosa.

encospe. Lo mismo que cospe.

enganecerse. Lo mismo que desmorecerse, pero refiriéndose solamente al llanto.

enganecido. Part. de enganecerse.

enganido. Encanijado.

engerecerse. [s.d.]

enguirrado. Esmurriado.

${ }^{49}$ Ensetar en HdlC. 
engruñar. Encoger.

enjibas. Encías.

enlorar. Liar o envolver algún objeto.

enregar. Hacer con el arado el primer surco al labrar un terreno. Empezar el primero a trabajar en una obra en que haya muchos operarios.

enría. Arriba.

enriba. Arriba.

entalarse. Quedar detenida una persona en su marcha porque sus ropas o carga que transporte se hayan trabado en algún objeto, o porque alguno de sus pies se hunda en agujero o hendidura del piso sin que lo pueda sacar al instante.- Tropezar algún objeto contra otro de tal modo que no pueda pasar de aquel sitio sin intervención de persona que de cualquier modo salve el obstáculo.

entaliscarse. Meterse en una talisca.

[entierro] intierro lleno. El entierro con funeral de primera clase.

entrada. Tollina.- Hablando de la comida, lo usan también en el sentido de darse un ataque o darse un atracón.

entrebucio. La persona que se introduce donde no la llaman o en asuntos que no le interesan.

entrementes. Entre tanto ${ }^{50}$.

entrijo. Redaño.

entrudo. Carnaval ${ }^{51}$.

enturriado. Hastiado, aburrido ${ }^{52}$.

envetado. Part. de envetar ${ }^{53}$.

envetarse. Meterse en un sitio rodeado de precipicios, del cual es muy difícil la salida sin ajeno auxilio.

envoldriar. Enturbiar, hacer perder la transparencia a algún líquido ${ }^{54}$.

escoplas. Coplas.

escosiñar. Movimientos más o menos rápidos hechos con las extremidades del cuerpo, como los que se ejecutan en la natación.

${ }^{50}$ Véase el port. entrementes, entremente 'entretanto; naquela ou nesta ocasião; tempo intermédio' (Figueiredo).

${ }^{51}$ Lugo.

${ }^{52}$ HdlC trae enturrio 'antipatía, repugnancia'.

${ }^{53} \mathrm{HdlC}$ recoge embetado.

${ }^{54}$ Normalmente ortografiado emboldriar. En portugués, emboldrear. 
esmurrado. Lo dicen por el instrumento cortante que ha perdido el filo. espajado. Esparcido.

espajar. Procurar alibio a algún pesar: espajar una pena.- Esparcir. Desvanecerse las señales de lluvia o tempestad.

espequero. El que maneja el espeque en las tiradas.

espequiar. Manejar el espeque en las tiradas.

esprimido. Avaro, miserable, mezquino.

estiada. En los días lluviosos, el momento en que escampa o cesa de llover. Lo mismo que clarea.

estiba. Astillas y demás pequeños residuos que quedan al labrar las maderas.

estilicón. Tirón.

estirizarse. Esperezarse.

estornizar. Estornudar.

estrello. Nombre que dan a la res vacuna que tiene una mancha blanca en medio de la testuz.

estropajar. Estropear o poner mal parada alguna cosa.

¡Oh, qué insolente!

¡Cómo estropaja

a rienda suelta

la gente honrada!

¡Oh, si el Demonio

te estropajara

con desvergüenzas

endemoniadas.

(Versos a D. Juan Mata Franco y Pagán, alcalde mayor que fue de esta isla. Autor desconocido).

[La letra $f$ falta en la colección de notas]

[G]

gachita. La cabra que tiene los dos cuernos combados hacia abajo, dando vuelta detrás de las orejas.

gafiando. Lo usan unido a todos los tiempos del verbo estar significando multitud. Así dicen: La Plaza está gafiando de gente; El trigo estaba gafiando de gorgojos. 
galana. La res vacuna de color blanco y el gatillo y barriga blanco pronunciado. galga. Piedra arrojadiza ${ }^{55}$.

galileos. Camino o sitio lleno de sinuosidades y asperezas, dificultoso y de mucho peligro.

galleta. Golpe dado con el puño en el rostro. Castaña.

gallofa. Reunión de trabajadores que, en un día determinado, se asocian para ayudar gratuitamente en una obra o trabajo a alguna persona, quien, a su vez, les obsequia dándoles de comer y beber en ese día.- Burla, chanza, chasco.

galludo. Ventrecha del pescado llamado tasarte, que, comida cruda, es muy sabrosa.

gambuesa. Terreno pedregoso que, por lo general, no se rotura ni se cultiva o cuya producción es tan escasa que no tiene importancia.

gangochería. Lo mismo que frangollería.

gangochero. Lo mismo que frangollero.- El que no es formal en sus negocios o contratos $^{56}$.

ganigote. Pierna delgada. Lo usan más generalmente en plural.

gaveta. Especie de artesa, de forma circular, que emplean en diferentes usos domésticos. Las de corto tamaño suelen tener una prolongación en forma de asa o mango.

gaviota. Nombre que dan a la cabra de color blanco, entero, y cuernos grandes abiertos y caídos hacia atrás.

generacio. Ascendencia.

gofio. Harina de uno o varios granos tostados, que constituye la base principal de la alimentación de los campesinos canarios. Es voz del perdido idioma guanche, de los cuales quedó la costumbre de comer los granos en esta forma.- gofio macho. El gofio hecho de aquellos granos que más sustancias alimenticias contienen, como el trigo, maíz, etc. Vélez de Aragón dice, equivocadamente en su Diccionario, que gofio es un provincialismo de Cuba. Bibliografía. Ligero estudio del gofio por D. Antonio Sánchez Reyes. Médico Militar, Caballero de la Orden de Alfonso XIII, etc. Impr. «Diario de Avisos», Santa Cruz de La Palma, 1903.

\footnotetext{
55 'Piedra lisa' en Lorenzo (28).

${ }^{56} \mathrm{HdlC}$, s.v. gangoche y gangochero.
} 
goro. El huevo que no está fecundado ${ }^{57}$.- La pocilga o zahúrda ${ }^{58}$.

grajita. La cabra de pelo negro y colorado entremezclado por el lomo y blanco el de la barriga y patas.

grama. Tosco artefacto de madera que sirve para quebrantar la parte leñosa del lino, a fin de separarla de la textil.

gramar. Quebrar con la grama la parte leñosa del lino.

grana. Enfermedad que suelen padecer los cerdos en los pueblos de Garafía y Puntagorda. Según el análisis practicado por el facultativo D. Elías Santos Abreu, dicha enfermedad es el Cysticercus cellulosae ${ }^{59}$, forma larvada de la tenia armada.

granel. La habitación de la casa más próxima al techo, que les sirve de despensa.Granero. "Que a su derecho conviene que algunos testigos de este lugar declaren lo que sepan o hayan oído decir sobre ciertos robos que a M. F. del mismo vecindario le han estado haciendo con llaves falsas tanto en el granel y lonja de la silla...». (Denuncia producida por D. Manuel Pérez de la Cruz, Alcalde de Tijarafe, en $1 .^{\circ}$ de febrero de 1830).

greta. Grieta.

[grita] dar grita. Llamar gritando a alguna persona que se halla a alguna distancia.

guanil. El ganado que está suelto, sin marca alguna.- El objeto que teniendo par se ha quedado sin compañero ${ }^{60}$.

guañar. Llorar un recién nacido.

guañido. Lloro del recién nacido.

güí. Interjec. La usan muy frecuentemente y en diferentes sentidos los naturales de La Palma.

guillado. Chiflado.

guillarse. Chiflarse.

gurrionero. Gorrista.

[gusto] pa mi gusto. Expresión que equivale a «para mi creencia», «a mi juicio», "A mi modo de entender».

${ }^{57}$ Además de 'huero, malogrado, hablando de huevos' goro también se aplica al chivo que no preña. También existe gorar(se) 'no salir del huevo' y, figuradamente, 'abortar, fracasar una empresa'. Véase HdlC, s.v.; Régulo Pérez (1970: 107); Pérez Vidal (1991: 244245); y Díaz Alayón (1990: 137).

${ }^{58}$ Lorenzo (32). Véase HdlC, s.v.; Régulo Pérez (1970: 125); Wölfel (1965: 475-476, 498); y Díaz Alayón (1987: 108-111).

${ }^{59}$ En el original, cellulocae.

${ }^{60}$ Lorenzo (33). 
[H]

[hombre] el hombre mío. Lo mismo que «mi hombre». mi hombre. Equivale $\mathrm{a}$ «mi marido».

[I]

¿iday? Expresión equivalente a «¿Y ahora?»; «¿Qué hacemos?»; ¿«Qué determinamos?».

[intre] en el intre. En el instante.

¡irria! Interj. que emplean para denotar horror, espanto. (jirra! escribió doña Emilia Pardo Bazán en su novela Una cristiana, Madrid, edición de la España Editorial, p. 16, lín. 25).

¡isiaj Interj.

islas (las). Expresión con que los campesinos de La Palma designan a las de Lanzarote y Fuerteventura.

[J]

jadario. Holgazán. Lo usan muy frecuentemente en el pueblo de Tijarafe.

jalada. Lo usan significando gran cantidad. Así dicen: Le dieron una jalada de palos (= muchos palos); Fuerte jalada de camino me di (= he caminado mucho; vine desde tal parte hasta aquí en tanto tiempo -corto para tal caminata-).

jalado. Borracho.

jaldruda. La cabra que de medio atrás tiene el pelo largo.

[jallo] jallo que. Frase equivalente a «creo que», «supongo que». jallo yo que. Lo mismo que jau yo que. jau yo que. Expresión que usan con los adverbios síy no y es equivalente a "supongo que es verdad»; «creo que síı; «creo que no».

jamponera. Lo aplican a la falda alta.

jarea. Pescado abierto y seco al sol.

jeito. Habilidad para hacer alguna cosa.- Luxación. En este caso suelen decir un mal jeito ${ }^{61}$.

jiga. La mano cerrada de forma que el dedo pulgar aparezca entre el índice y el corazón.- Figura de oro, plata o madera que representa la mano en la forma dicha y que se coloca atada a la muñeca de los niños, como amuleto. Conceden gran eficacia a las jigas hechas de madera de ruda salvaje. - hacer

\footnotetext{
${ }^{61}$ Lugo.
} 
jigas. Poner una mano o ambas en la forma indicada para evitar el mal de ojo o cualquier otra influencia maligna ${ }^{62}$.

jilorio. Lo mismo que ajilorio.

jimpo. Hipo.

jímpole. Lo mismo que jimpo.

jinchete. Golpe fuerte del cuerpo contra el suelo.

[jindi] jindi bien. Expresión que usan en la villa de Mazo y en el pueblo de Fuencaliente de La Palma por vía de saludo o en señal de que aprueban o aplauden lo hecho por alguien ${ }^{63}$. jíndilo bien. Lo mismo que jindi bien.

jitera. Hartazgo.

jolgazano, na. Holgado, ancho.

[jormiga] cargar a la jormiga. Transportar una sola persona varias cargas a un mismo tiempo, llevándolas una a una a cortos trechos, retrocediendo luego a buscar las que se han dejado más atrás, y así sucesivamente.

juelgazano, na. Holgado ancho.

juicio. Palo redondo que colocan sobre el pie o queso que forman en los lagares para prensar la uva.

jurgonero. Barrendero del horno. Se aplica a todo aquello que, por su suciedad, se asemeja al barrendero.

jurria. Muchedumbre.- Voz con que ahuyentan a los animales.

\section{[L]}

laboria. Labranza del campo.

labutante. Lo usan precedido del verbo tener, y de los adverbios tan, más, menos, muy, para indicar las relaciones de amistad más o menos íntimas que llevan con una persona, p. e.: A esa persona no la tengo muy labutante ${ }^{64}$.

labutar. Habitar.

lagareta. Depósito hecho de madera de tea, en forma rectangular, para recoger el mosto que corre de la uva exprimida en el lagar ${ }^{65}$.

lambido, da. Persona de poca vergüenza.- Hombre lampiño.

${ }^{62}$ HdlC, s.v. giga.

${ }^{63}$ Lemos Smalley le da a esta expresión el valor de 'me alegro mucho' (596).

${ }^{64}$ Régulo Pérez (1970: 148) trae labutante 'conocido, tratado, familiar' y labutar 'habitar, conocer, familiarizarse'. Véase el valor alentejano de labutação 'trato, relações, privança: não tenho labutação com essa gente' (Figueiredo).

${ }^{65}$ En español existe lagareta, pero con unos sentidos lejanos del uso canario, que sí coincide con los valores portugueses. Véase Pérez Vidal (1991: 220) y ALEICan, mapa 148. 
lamero. Lamedal.

lantrico, ca. Lo mismo que lambido.

lanza. Especie de cayado, recto, de 2 a $2^{1 / 2}$ metros de largo, redondeado y pulimentado, a cuyo extremo superior ponen un casquillo y en el inferior un regatón de hierro, de un pie de largo y en forma puntiaguda. Lo usan para ayudarse cuando caminan, y apoyados en ella salvan precipicios y descienden ágilmente por los despeñaderos con asombrosa rapidez.

lapero. Instrumento de hierro que sirve para separar o desprender la lapa de la piedra.

lapiador, dora. El que acostumbra ir a cojer lapas.

lapiar. Cojer lapas.

látigo. Correa de cuero de tres pulgadas de ancho y dos metros aproximadamente de largo, cosida por sus extremos, que doblan en 4 partes, para sujetar con ella el palo del arado a la canga, travándola con la chaveta.- látigo de suela. Tira de piel de buey, sin curtir, de todo el largo del cuero y ancho de una cuarta próximamente, de la cual sacan la suela para el calzado llamado de suela cruda.

[lebeta] una lebeta. Una contrariedad.

[leche] leche pisada. La leche que adquiere un color rojizo a causa de haberse lastimado la ubre del animal.

lepidioso, sa. Impertinente.

[licencia] con licencia. Frase que equivale a con su permiso, con permiso de Vd.- También se oye: Con su licencia.

[lienzo] lienzo casero. El tejido de lino o cáñamo fabricado en el país.

liña. Cordel.

lisio, sia. Liso.

lonja. Accesoria ${ }^{66}$.

lostra. Costra formada por granos, erupciones o ronchas en la piel.

[luces] entre dos luces. Hora de los crepúsculos.

[lufes] lufes no lufes. Lo mismo que entre dos luces.

lusio, sia. Liso.

\section{[M]}

macana. Cobarde.- Palo pequeño que se usa como arma.

${ }^{66}$ Lugo. 
mago. Campesino ${ }^{67}$.

magrera. Pringue, suciedad.

malpéis. Mal país, terreno quemado por los volcanes. «Y asimismo compramos la mitad del cercado que dicen del Negro y de la Portada en dicho lugar [Tajuya] que el todo de ello linda por arriba camino real que va a Las Manchas el malpéis que dicen de Gaspar González por abajo y un lado tierra de María Hernández...». (Testamento del Alférez Bartolomé Martín Corral y su mujer Ana Hernández, vecinos de Los Llanos. Falta la fecha) ${ }^{68}$.

mampiar. Tragar, comer excesivamente.- Hacerse con lo ajeno.

maneta. La cabra que tiene blanco el pelo de una de las patas.

mángara. Enfermedad que ataca a los árboles.

manguillir. Sumergirse. El Sr. Franchy y Roca dice que esta palabra ha sido tomada del portugués. Véase el artículo ya citado «Cómo hablan los canarios» ${ }^{69}$.

[manteca] manteca nula. Manteca hecha de leche de cabras, a la que se atribuyen virtudes curativas ${ }^{70}$.

manzano. Nombre que dan al buey de color blanco ${ }^{71}$.

marmaruta. Conversación o monólogo sostenido a media voz.- Murmullo incoherente o poco perceptible.

marranete. Cada uno de los varios trozos de madera que se colocan en los lagares en sentido inverso al de las cabrillas y sobre éstas, hasta alcanzar la altura necesaria para que la viga, al descender, haga presión sobre ellos y exprima el bagazo a fin de que arroje el líquido que aún contenga.

masapés. Tierra arcillosa ${ }^{72}$.

matraca (la). La tabla con un agujero circular donde entra y gira la parte superior del palo del molino llamado de mano.

mazaroca. Mazorca; lo mismo cuando se refieren a la del maíz, como a la cantidad de hilado que puede contener el huso.

meda. Grupo o hacinamiento de haces de cereales, hecho en forma cuadrangular, en el cual colocan la espiga para el centro del grupo. «...en las cuales tierras

${ }^{67}$ Resulta curioso que mago no aparezca en Lemos Smalley. HdlC también refleja el término y, además, recoge el dicho Mago tolete debajo del puente turre cochino regaña el diente, popular en Santa Cruz de La Palma.

${ }^{68}$ HdlC refleja malpaís y malpéis.

${ }^{69}$ Más frecuentemente, margullar y margullir, formas que, además del valor de 'nadar bajo el agua', tienen el de 'acodar, principalmente la vid'.

${ }^{70}$ Es el amolán de otras hablas insulares.

${ }^{71} \mathrm{HdlC}$ trae mansano como 'buey claro'.

${ }^{72}$ Sobre las distintas etimologías véase Díaz Alayón (1987: 127-129). 
está una hera onde se recoxe el grano y algunas personas con poco temor de Dios y menosprecio de la Real Justicia an soltado sus ganados ovejunos antes del tiempo que se acostumbra y han dañado una meda de $\mathrm{c}^{\text {no }}$, y para que se castigue...». (Querella presentada por D. Juan Francisco Taño ante el Alcalde de Los Llanos, D. José Cayetano de Alcalá, en 5 de junio de 1749).

mestura. Salvado.

millisco. Pequeñísima parte de un todo.

[mío] el mío. Lo mismo que «mi hombre».

[misma] con la misma. Mod. adv. Lo dicen para dar a entender que en el mismo instante que terminaron el asunto que los retenía en alguna parte, se marcharon. Fui a misa, y con la misma me vine pa casa; Fui a la sala y con la misma me vine; Cené y con la misma me acosté.

mocana. La cabra cuyo pelo es negro.

mochilla. Mochila.

mojo. Salsa cruda. En La Palma se hace machacando pimienta verde o madura, esta última previamente cocida, ajos y sal, añadiéndole luego aceite, vinagre y agua. También suele ponérsele pimentón molido, cominos y silantro. En el pueblo de Tazacorte, tienen especialidad en la confección del mojo, principalmente del que hacen para exportar a Cuba, al que sólo ponen gran cantidad de pimienta madura, cocida y desprovista de venas y semilla, muchos ajos y sal; todo bien machacado hasta formar una pasta suave y espesa a la que añaden aceite y luego al servirlo le ponen el agua y vinagre a gusto del consumidor.- mojo hervido. Se hace en la forma indicada para el crudo, o añadiéndole algún otro ingrediente e hirviéndolo en el pescado o carne.

Y tinas bien rellenas de chicharros

asados y anegados en el mojo

( «Las vendimias en el Barranco de Maldonado». Poema en un solo canto.- Por un amante de las bellezas del campo.- 1830).

molero. Piedra.

mollero. Molledo. Generalmente lo usan en plural: Tiene buenos molleros.

mondisalla. Reunión de chiquillos ${ }^{73}$.

montina. Enfermedad que ataca principalmente a la cabeza, con náuseas, hinchazón en las orejas, escalofríos, fiebre e inapetencia. Suele ir acompañada de erisipela.

\footnotetext{
${ }^{73}$ Lorenzo, s.v. mondiza.
} 
[mor] dar mor de sí. Dar señales de vida. por mor de. Frase que equivale a «por culpa de», "por causa de»; y así dicen: Por mor de ti llegué tarde; No pude venir por mor del tiempo.

morisca. La cabra que tiene el pelo blanco y gris oscuro o blanco y negro entremezclado.

morón. Palo grueso del cual se sirven como auxiliar para bajar maderas por grandes pendientes o descolgarlas por precipicios. Clavado fuertemente el morón en la tierra, pasan una gruesa cuerda alrededor de él, con una sola vuelta, al extremo de la cual cuerda atan la pieza de madera que desean bajar o descolgar; el extremo opuesto lo sostiene un hombre que va graduando la velocidad con que desciende la pieza, por la mayor o menor tensión que da a la cuerda. A este ejercicio llaman dar morón.

[moza] la moza. La novia.

[mueca] la mueca. Ceremonia que se supone se celebra en Santa Cruz de La Palma el Viernes Santo, y a la cual se invita a los forasteros llegados a la isla, ofreciéndoles ridículos premios si se prestan a tomar parte en la solemnidad, ya para dar el espirido o el cebo a la cuña o bien para manejar la mandarria, etc. Es antiquísima en nuestra ciudad esta broma que algunos, con demasiada candidez, han tomado en serio, y que en ocasiones ha dado lugar a incidentes más o menos desagradables.

murgaño. Ratón pequeño ${ }^{74}$.

\section{[N]}

navidad. Época, tiempo. Así dicen: Este árbol tiene fruta de dos navidades, Este cabrito es de otra navidad que aquél; Aquí hay pichones de varias navidades. Lo usan más frecuentemente en plural.

negallo. Madeja.

nombrete. Apodo.

novelo. Ovillo ${ }^{75}$.

nuevo. Joven.

\section{[Ñ]}

ñáñaras. Narices.

ñañas. Narices.

${ }^{74}$ Lugo y HdlC, que trae burgaño, murgaño y murgañera 'madriguera de ratones pequeños'.

${ }^{75}$ Lugo. Véase el port. novelo. 
ñisca. Excremento humano.

[O]

¿olo? Lo mismo que ¿Dónde está?, ¿A verlo?

ondia. Ceguera, vahído.

oriscana. La cabra que tiene el pelo de las orejas blanco y de distinto color lo demás del cuerpo.

\section{[P]}

pabujal. El terreno que se deja de relva par pastorear en él el ganado.- Sembrado anémico y desmedrado.

pajero. Edificio pequeño cubierto de paja de centeno.

pajonal. Terreno cubierto de yerba seca.

palmerada. Especie de splen [sic] que padecían los aborígenes palmeros y que ha llegado hasta nosotros. "...y porque aquí no hay más diverción, y si falta ésta nos vamos a aburrir de lo lindo, y nos exponemos a que nos dé la funesta endémica palmerada». (De un artículo publicado en el n. ${ }^{\circ} 28$ del periódico El Clarín, de esta ciudad, correspondiente al 1. ${ }^{\circ}$ de mayo de 1871).

palmita. La res vacuna de color blancuzco.

pampanada. Remeros de haya, vid, etc.

[pan] pan de leche. Este pan, que se fabrica principalmente en Garafía, Puntagorda y Puntallana, en las fiestas principales de cada una de estas localidades, se hace añadiendo a la harina leche cuajada, azúcar, huevos, canela, raspaduras de limón, azúcar y un poco de vino. pan de manteca. Se fabrica en toda la isla, pero especialmente en Santa Cruz de La Palma y por la Pascua de Navidad. Se confecciona añadiendo a la harina manteca de cerdo y de vacas, azúcar, canela, matalahúga y un poco de vino. En los días indicados se vende este pan a domicilio en forma de tortas, roscas, etc. pan de moniato. Se fabrica en la ciudad de San Andrés y Sauces, añadiendo a la harina, en lugar de agua, pasta de moniato cocido. Resulta moreno, pero muy sabroso ${ }^{76}$.

pancada. Golpe dado con la mano abierta en las espaldas de otro.

parchazo. Golpe que recibe un cuerpo al caer tendido al suelo.

parecencia. Parecido, semejanza.

${ }^{76} \mathrm{HdlC}$ también refleja moniato, lo que parece indicar que a finales del siglo XIX esta forma (a veces muniato) parece ser general entre los hablantes cultos de La Palma. 
parría. Para arriba.

[payol] a payol. Mod. adv. En montón.

pecuña. Pequeño trozo de tierra.

pejinca. Persona débil, enclenque, de poco ánimo. Tiene una sola terminación para ambos sexos.

[pejo] jacer pejo la comida. Indigestársele a uno la comida.

peldriango. Cualquier objeto que cuelga. Se usa mucho en el pueblo de Tijarafe. [pelo] cojerse el pelo. Peinarse.

pendanga. Piedra que los pescadores atan en la cuerda cuando pescan de tierra, para poderla lanzar a larga distancia.

penitente. Palo de la planta llamada pitera, cuando está florida.

perdurable. Cosa de poca duración, de poca vida.

perenquén. Cierta clase de lagarto pequeño. Nuestro sabio comprovinciano don José Viera y Clavijo, en su Diccionario, le da el nombre de perinquén y dice que es el Lacerta turcica de Linneo ${ }^{77}$.

perincanco. Cualquier objeto que cuelga.

perrez. Fuerte rabieta que no permite al que la sufre ceder ni darse a partido.

petaco. Lo mismo que velillo.

picarda. La cabra que tiene el pelo jaspeado de tres distintos colores.

[pieza] sacado de la pieza. Se dice que ha quedado en tal forma la persona a quien de alguna manera se ha insultado sacando a relucir sus defectos.

pilla. Pila o montón de pescado salpreso. Más salado que la pilla = muy salado ${ }^{78}$. pingar. Gotear, caer algún líquido gota a gota.

pingora. La rama más alta de un árbol.

plaga. Maldición. ¡Mal rayo te parta! ¡Los demonios te carguen! ¡Los demonios te apotequen! ¡Mal risco te vuele! plaga jonda. Horrorosa maldición: ¡Los demonios te devanen las tripas en un sarillo! ;Los demonios te lleven en cuerpo y alma! ¡Cojido de moros seas tú! ¡En prisiones mueras! ¡Los cuervos te saquen los ojos! ¡Fuga de risco vueles y no encuentres charamusca en que agarrarte y el papo del cuervo te sirva de sepultura!

pos. Pues.

[poseo] poseo de calabozo. Acto de posesión que hacen en los terrenos llamados de quinto, en el pueblo de Garafía, cortando con un calabozo árboles y ramas gruesas. Esta posesión queda sin efecto si a los tres meses no se ha

\footnotetext{
${ }^{77}$ Lugo.

${ }^{78}$ Lugo. Véase la expresión lusa salgado como a pilha.
} 
preparado para la siembra la tierra objeto de la posesión. Es costumbre antiquísima la adquisición de terrenos en el quinto en la forma expresada. poseo de jacha. Acto de posesión que hacen en los terrenos llamados de quinto, en el pueblo de Garafía, cortando con hacha árboles y ramas gruesas. Esta posesión queda sin efecto si a los seis meses no se ha preparado para la siembra la tierra objeto de la posesión. Es costumbre antiquísima la adquisición de terrenos en el quinto en la forma expresada.

poteras. Las uñas.

precondio, a. Decrépito.

preguisa. Pereza ${ }^{79}$.

[prepingo] de prepingo. Constantemente.

privación. Alegría.

privado, da. Alegre, contento.

[pueblo] dar al pueblo. El acto de comunicar el Alcalde alguna disposición al pueblo, hallándose este reunido. Se hace en días festivos, a la salida de la misa conventual, en la plaza de la iglesia, colocándose sobre un muro, escalinata u otro sitio elevado, para ser visto y oído de todos, pero cuyo sitio es siempre el mismo en cada pueblo. La alocución comienza con estas frases: «Señores vecinos», y termina generalmente con las siguientes: «Y con esto vayan ustedes con Dios». Al comenzar y al terminar saluda a los vecinos, quienes devuelven el saludo.- En algunos pueblos se ha suprimido ya esta antiquísima costumbre. juntar el pueblo. Reunir el Alcalde al vecindario a la salida de misa conventual para comunicarle alguna disposición. Antiguamente decía el Alcalde: Júntese el pueblo. Hoy basta para que se reúna que se coloque en el sitio señalado para dar al pueblo.

[puerta] coja la puerta. Loc. fam. equivalente a iMárchese Vd.!, ;Váyase Vd.!

[pulso] pulso de la camisa. Puño, parte del lienzo que en la camisa está unido a la bocamanga.

pútiga. Especie de seta que crece al pie de las jaras. Es de forma semejante a una piña, de color rojo y amarillo al exterior y jugosa. Algunos campesinos la comen.

puy. Equivale a por, y la emplean con los adverbios arriba, abajo, allá, acá.

${ }^{79}$ Véase el portugués preguiça 'morosidade, negligência; vontade de não trabalhar, desamor ao trabalho; pachorra, moleza, indolência' (Figueiredo). 


\section{[R]}

ramal. Trozo de tela que a manera de capa se ponen las mujeres, especialmente en el pueblo de Tijarafe.

[ramo] ramo del cura (el). Gajo copioso, generalmente de haya, que, muy adornado con frutos de la época, roscas y flores, colocan al pie de la escalinata del púlpito, en las festividades religiosas que celebran las cofradías. Terminada la solemnidad, es llevado a la casa rectoral por el Hermano Mayor, quien lo entrega al párroco.

rasquera. Sarna.

ratiño, ña. Hablando de las medidas, lo mismo que escasas. Cuando se refiere a las personas, el que da de todo la menor cantidad posible.

rayadero. Palo redondo que, al medir rayo los áridos, se pasa por cima de la medida para que el contenido no sobresalga de los bordes.

rayo, ya. Forma o manera de medir los áridos exactamente, de modo que no rebacen los bordes de la medida.

rebanadas. Se hacen en varios pueblos de la isla, sobre todo para los refrescos en bodas y bautizos. Las confeccionan con rodajas de pan que remojan en leche azucarada y recubren con huevos batidos, friéndolas con manteca y sumerjiéndolas luego en miel de abejas.

rebenques. Ropa vieja y casi inservible ${ }^{80}$.

rebujón. Alboroto, bullicio.- Envoltorio.- Dícese también de un objeto o asunto enmarañado o enredado.

recachar. Recoger el resto de las cosechas.

rechinchudo, da. Rechoncho.- La persona fatua y orgullosa.

regañado, da. Regañón.

regañisas. Muecas hechas con la boca.

regatoniar. Dar golpes con el regatón de la lanza al servirse de ella para caminar. Lo dicen también por el ruido que produce el golpe.

regazada. Lo que se puede contener en el hueco que forman con la enagua, recogiendo su delantera y trabándola a los lados de la cintura.

rejartero, ra. Desconfiado, receloso.

rejelada. Helada.

rejielo. Hielo.

En la cumbre no hay claveles

${ }^{80}$ HdlC trae para rebenque los valores de 'ovillo de hilo en forma de madeja'; 'persona bruta'; y 'palo en forma de látigo'. 
porque los mató el rejielo,

y en tu cara sí los hay

porque lo premite el cielo.

(Copla popular campesina).

relación. Copla o cantar.

Váyanse pasando

de aquí para allá

que las relaciones

se van a cantar.

relingo. Salto, brinco, juego.

remejedero. Utensilio que se usa para revolver los granos al tostarlos, y que se compone de un palo con un envoltorio de trapo a uno de sus extremos ${ }^{81}$ :

Ayúdame, San Pedro,

tú con la pala,

yo con el remejedero.

remocada. Respuesta altanera e insolente.

remujar. Resonjar.

remujón. Persona que regaña con frecuencia por todo.- Regaño.

rente. Lo mismo que cerce.- Al rape, por el pelo ${ }^{82}$.

repostada. Respuesta altanera e insolente.

requemada. La cabra que tiene el pelo de los cuartos delanteros de un color, el de los traseros de otro, y el resto del cuerpo negro.

responder. Coro o estribillo con que en sus cantigas acompañan el romance. Hay estribillo que sólo se canta con determinado romance y otros que se acomodan a todos. Tienen muchos.

[rifasol] a su rifasol. Loc. fam. A su libre albedrío.

[riza] de risa. Patatas o cereales que nacen sin que a su tiempo y previamente se hayan sembrado, sino que tienen su origen en semillas abandonadas de cosechas anteriores.- Se dice también de los hijos de padres desconocidos.

rizadera. Vara larga con un calabozo en uno de sus extremos. La usan en la ciudad de San Andrés y Sauces.

\footnotetext{
${ }^{81} \mathrm{HdlC}$ también lo trae como estopero, mejeriquero (s.v. estopero) y remejequero.

${ }^{82}$ Lugo.
} 
rodilla. [s.d. $]^{83}$.

rolón. El gofio que por defecto de la molturación quedó demasiado grueso.

romero. Nombre que dan a la res vacuna de pelo colorado y cabeza y hocico negros.

roña. Incomodidad, cólera, inquina.

roñoso, sa. Enfadado, incómodo, molesto.

rosilla. La cabra que tiene el pelo blanco y gris claro.

[S]

sajonada. Nombre que dan a la cabra de pelo de varios colores obscuros muy pronunciados y entremezclados.

[salida] una salida. Frase que indica en la villa de Garafía que sale el Viático. Hoy hay una salida equivale a "Hoy sale el Viático». El cura fue a una salida por «El cura fue a llevar el Viático».

salir. Subir.

salón. Terreno arcilloso ${ }^{84}$.

[salud] apreciando la salú. Expresión que emplean muy frecuentemente al despedirse.

salvante. Con exclusión o excepción de alguna cosa.

[santodomingo] santo domingo. Baile que estuvo muy generalizado entre los campesinos de La Palma.

sarabio, bia. Lo que es muy picante al paladar.- La persona de mal genio ${ }^{85}$.

sargo. Persona astuta a quien es difícil engañar.

sarnar. Hacer un corte circular en los troncos de los árboles, quitándoles la corteza, para que el derrame de la savia ocasione la pérdida de los vegetales ${ }^{86}$.

sato, ta. Persona o animal de piernas cortas con relación al tamaño del cuerpo ${ }^{87}$. sedero. Rastrillo, instrumento que sirve para asedar el lino o cáñamo.

seña. Tratamiento equivalente a Señora.

síque. Sí, en la villa de El Paso.

${ }^{83}$ Rodete o rosca de lienzo, paño u otra materia que se pone en la cabeza para llevar sobre ella una carga. Véase suegra.

${ }^{84}$ Esta voz hay que vincularla a formas del área luso-galaica. En portugués, solão y salão.

${ }^{85}$ En portugués, saraivo.

${ }^{86}$ Véase cernar.

${ }^{87}$ Lorenzo (41). 
sirinoque. Baile que estuvo muy en moda entre los campesinos de La Palma. síse. Apócope de sí señor.

solabanco. La ola del mar ${ }^{88}$.

solera. Pértiga de uno o dos decímetros de diámetro y algunos metros de largo. Generalmente la hacen del palo central de un árbol joven.

[sopa] sopas de miel. Esta sopa que en casi todas las casas de Santa Cruz de La Palma se hace por las fiestas de Carnaval se confecciona haciendo hervir miel de caña, a la que se añade canela, cortezas de limón, matalahúga y rodajas de pan suficientes para que absorvan todo el líquido, y luego se sirven en frío. También suelen ponerles almendran dulces fritas y molidas.

sotro. Esotro.

suegra. Rodilla ${ }^{89}$.

suiste. Lo usan en la villa de El Paso para ahuyentar a los asnos.

[T]

tabacazo. Golpe.

tabuco. Lo mismo que cabuco.

talegazo. Lo mismo que costalazo.

taliano. El que tiene dificultad para pronunciar.

talisca. Desigualdad del terreno que presenta grietas estrechas, de poca profundidad.

tallero. La alacena o armazón de madera donde colocan la loza y la talla con el agua.

taño. Utensilio donde guardan la sal; lo hacen de paja y más generalmente de un trozo de drago ahuecado ${ }^{90}$.

tapume. Trama, hablando de las telas.

tareco. Mueble u objeto de poco valor y mérito.

Ninguno se maravilla

que lloren los desgraciados

que de sus casas vieron

que ni las puertas cerraron,

${ }^{88}$ Véase banco de mar en Lugo.

${ }^{89}$ En portugués, sogra.

${ }^{90}$ Figueiredo recoge tanho como provincialismo del Algarve con el valor de 'grande seirão. próprio para conter cereais'. 
sin sacar siquiera de ella,

el tareco más libiano.

( Historia». Romance de Martín Lorenzo Martín, natural de Garafía, al gran incendio ocurrido en los montes de aquella villa, el 12 de agosto de 1902).

tarro. Asta (cuerno).

templa. Pieza que, en los lagares, pasa de una a otra curiña para que sobre ella descanse la viga.

templumes. Las especias con que sazonan las comidas.

[tener] a tener. Ir a entrevistarse con determinada persona, p. e., Voy a tener con el alcalde; Fui a tener con don Fulano. Lo usan precedido del verbo $i^{91}$.

tengue. Tome.

tenique. Piedra ${ }^{92}$.

[teque] teque que teque. Expresión que equivale a «poco a poco», "pasito a pasito».

[tetera] tetera blanca. Enfermedad que ataca a la ubre de las cabras. Esta se pone tumefacta y la lecha no sale al exterior, sino en muy corta cantidad y difícilmente, causando la muerte de muchas, aunque suelen curarlas con emplastos de las yerbas llamadas Santa María, vinagrera y otros remedios. tetera negra. Enfermedad que igualmente ataca a la ubre de las cabras; pero no puede curarse. Es una especie de gangrena que les destruye la ubre, la cual se les cae a veces a trozos. Generalmente no resisten más de 24 horas los efectos de tan terrible mal.

[tientitas] a tientitas. Mod. adv. Hacer una cosa sigilosamente y con cautela.

tiesto. Por tostador, como instrumento en que se tuesta.- Lo emplean también como término despectivo para insultar a una persona ${ }^{93}$.

time. Risco alto, eminencia. Es voz del perdido dialecto de los indígenas palmeros, que pasó a nuestro léxico y se usó con la misma significación de altura, eminencia, cima. Actualmente sólo se ha conservado la voz time como nombre de una parte de la cordillera que termina en la Punta de Juan Graje y el Puerto de Tazacorte ${ }^{94}$. «El Capitán por S. M. D. Matías de Escobar Pereyra Regidor perpetuo de esta isla como Mayordomo que soy de la Hermita de ntra. Sra. de la Concepción del lugar de Buena vista paresco ante Vmd. y digo: Que siendo anexo y perteneciente a dha. Yglesia el cerco de ella y el paso desde dha. Yglesia hasta la cruz y su contorno el time del risco y su

\footnotetext{
${ }^{91}$ Millares Cubas, s.v. ir a tener.

92 'Piedra piquenta' para Lorenzo (45). Véase Wölfel (1965: 537-538).

${ }^{93}$ Lugo y HdlC.

${ }^{94}$ Lorenzo (46-47). Véase Díaz Alayón (1987b: 157-158) y Wölfel (1965: 374, 596-598).
} 
pendiente hasta las tierras labradías...». (Escrito del expresado D. Matías de Escobar Pereyra presentado al Teniente General de esta isla Licdo. D. Juan Bautista Poggio, en 2 de diciembre de 1676). En 20 de marzo de 1751, Dionisio García, Alcalde de Garafía, a virtud de auto del Teniente General de La Palma, que lo era D. Pedro Escobar y Espicer, mandó medir y deslindar seis fanegas de tierra en el sitio y llano de San Antonio, que era de dicha ermita, y dice: «y por arriba linda la vera del Barranquillo de detrás de dha. Hermita hasta el time de la montaña; y . $^{\mathrm{r}}$ abajo lo último del llano y pr. un lado el camino Real y por otro cuasi el time de dha. Montaña». (De un manuscrito que se conserva en el archivo de la parroquia de N. S. de la Luz, de Garafía). «Una propiedad de viña de malvasía y vidueño en el barranco que dicen de los molinos que linda por arriba la time del lomo de los molinos...». (Inventario de los bienes quedados por fallecimiento de D. ${ }^{a}$ María Massieu Vandala).

tinete. Tema, majadería, mal hábito ${ }^{95}$.

tiniquiar. Pescar con cuerda desde tierra.

tiñuela. Cierta enfermedad que ataca a las patas de los gallos y gallinas.

tirijala. Dulce correoso, hecho con miel, aceite y harina, que afecta la forma de una tira de tela que se ha doblado y torcido.- Cualquier objeto largo y delgado.- Camino de mucha extensión ${ }^{96}$.

tiritaña. Tela burda de lana del país, de que generalmente hacen sus trajes los campesinos de Barlovento, Garafía, Puntagorda y Tijarafe.

topo. Terreno prominente.

trabajoso, sa. Enfermo grave.

trafallo. Desperdicio, desecho, cosa inútil ${ }^{97}$.

trapaleta. [s.d. $]^{98}$.

trapera. Manta tejida en el país, cuya urdimbre es de lino o cáñamo y la trama de tiras de tela. Suelen teñir estas tiras de diferentes colores ${ }^{99}$.

trapiche. Quehacer u ocupación que exige mucha actividad o movimientos.

traquiado. Entendido, práctico en alguna cosa ${ }^{100}$.

travezada. Almorzada.

${ }^{95}$ Lugo y HdlC.

${ }^{96}$ HdlC.

${ }^{97}$ Véase chafallo.

${ }^{98} \mathrm{HdlC}$ aporta los valores de 'accidente, desvanecimiento', 'enfermedad leve y repentina' y 'pérdida momentánea de sus facultades mentales'.

${ }^{99}$ HdlC.

${ }^{100}$ HdlC trae traqueado y los Millares Cubas anotan traqueteado. 
tredo, da. Discreto, ingenioso, agudo ${ }^{101}$.

treslado. Parecido, semejanza.

[trir] a trir por hay. Expresión con que dan a entender que tal o cual prenda de vestir o calzar la han destinado al uso diario.

trópico, ca. El que padece hidropesía.- La persona que por enfermedad o defecto físico tiene flojedad en las piernas ${ }^{102}$.

trujanero, ra. Persona aficionada a usar trujanes.

Dices que canto trujanes

y que soy la trujanera,

más vale cantar trujanes

que andar con vidas ajenas.

(Copla campesina)

tunera. Nopal. "Yten mandamos que si quedase por nuestro fallecimiento y si estuviese en nuestra compaña Francisco Hernández Rolo, dejamos para él y quien su causa hubiere la suerte de tierra de viña y árboles con sus tuneras en los lomos donde llaman Juan de Alcalá...». (Testamento de D. José Manuel Cordovés Hernández y su mujer D. ${ }^{a}$ Cayetana Rodríguez Felipe, vecinos de Los Llanos, otorgado el 26 de diciembre de 1831).

tuno. El fruto de la tunera.

[tútano] tútano de mayo. El tuétano de las reses vacunas que matan en el mes de mayo, a cuyo tuétano atribuyen propiedades medicinales.

[U]

¿úlo? ¿Dónde?

[V]

vajo. Vaho ${ }^{103}$.

vaqueta. Cobarde ${ }^{104}$.

varales. Camilla, cama portátil.

varanca. Gajo largo de cualquier árbol, limpio de ramas.

${ }^{101}$ Se aplica mucho a los niños. Registros en HdlC, s.v. y Régulo Pérez (1970: 110).

Véanse las formas lusas tredo y trefo.

${ }^{102} \mathrm{HdlC}$. En portugués, trôpego.

${ }^{103}$ En HdlC bajarada 'aire caliente' y bajear 'vahear'.

${ }^{104}$ HdlC. 
varancón. Aumentativo de varanca.

[varqui] varqui aquí. Lo mismo que verque aquí. varqui pa qui. Lo mismo que verque aquí.

velete. La leche que en los nueve días siguientes al parto dan las personas y los animales ${ }^{105}$.

[verga] verga del cura. Asta que los vecinos de Breña Alta colocaban en la Plaza de la Constitución de Santa Cruz de La Palma, con motivo de la novena que aquel pueblo hacía a la Virgen de las Nieves en sus bajadas periódicas a esta población.- El asta, adornada con ramas y flores y con su correspondiente bandera, era conducida en la mañana del día en que se celebraba la novena por gran número de campesinos de Breña Alta, que entonaban sus cantigas acompañándose con el tambor. También figuraba en la comitiva un grupo de hermosas lugareñas portando cestas con flores con que decorar el templo.- Hace años que no se realiza tan típico festejo.

[verqué] verqué aquí. Expresión con que advierten al ganado vacuno y mular que dejen la dirección que han tomado y sigan la que quiere el que los guía.

veta. Pequeña planicie en las laderas y riscos, de difícil entrada y salida ${ }^{106}$.

[virar] birado de conchas. Tendido de espaldas.

[vos] en vos de. En pos de.

\section{$[\mathrm{X}]$}

xínifa. La cabra que tiene el pelo blancasco, con listas de otros colores todos pálidos $^{107}$.

\section{[Z]}

[zapato] zapato de resbalón. El zapato cuya suela es corrida, sin tacón alguno. zapato de tacón. El zapato que tiene el correspondiente tacón.

zarillar. Devanar con el zarillo el lino, lana, etc., ya hilado para formar madejas $^{108}$.

zarillo. Palo de dos pies de largo aproximadamente, que tiene en sus extremos otros más cortos colocados horizontalmente y en sentido opuesto uno al otro, en los cuales traban las hebras del hilado para formar la madeja.

${ }^{105}$ HdlC, s.v. belete. Véase Wölfel (1965: 522).

${ }^{106}$ En HdlC, beta 'lugar donde se está embetado' y embetado 'persona o animal sin salida en un precipicio'.

${ }^{107}$ Así en el original, pero los estudiosos del léxico insular traen sínifa.

${ }^{108}$ Lugo, s.v. sarillary sarillo. Véase las formas lusas sarilhar, ensarilhary sarilho. 
zumbina. Aguacero. - Borrachera.

zurrumacre. Suciedad, pringue.

\section{APÉNDICE DE MAX STEFFEN}

Una vez terminada la copia precedente, verifiqué cada una de las palabras contenidas en ella con doña Emérita Pérez Rodríguez, de Garafía, de 61 años de edad, y uno de los mejores informadores que he encontrado. Esta comprobación me permitió ver que el Sr. Pestana Rodríguez trabajó con mucho cuidado y escrupulosidad y que sus referencias son muy de fiar. No obstante, hay algunas variantes y acepciones distintas, junto con alguna palabra o giro nuevo, que salieron a luz al verificar el vocabulario. Estas variantes y palabras nuevas son las que van a continuación.

ajoriar. Ahuyentar a los animales.

andar a la deburga. Lo mismo que andar a brucas.

a su rifasol. Se dice también andar a su rianda suelta.

ansias. Se dice también provocaciones.

atorgado. Se dice más comúnmente aturgado.

bambaraso. Golpe.

bandola. Cada uno de los lados de la madera labrada en bruto.

basurdo. Montón de basura.

birado de conchas. Se dice también comúnmente birao de patas.

boquete / boqueta. Boca hecha en el filo de una herramienta, como un podón, hacha, cuchillo, machete, etc.

borsolana. Se dice también bursulana = palangana.

bimba. Piedra grande que puede manejar un hombre.

cadillos. Las hebras que quedan sin tejer al principio y fin de la tela en los telares insulares.

cachasa. Calma: Aquél sí que tiene cachasa.- En pl., quijadas.

cachorra. Calabaza de agua usada para transportar vino.

carranca. Arrancada, desplazamiento brusco de un sitio.

carrumba. Montón.

chaveroso, sa. Persona de mala boca.

chucallero, ra. Persona que anda con engañifas. 
churumisgar. Llover con lluvia menuda.

comichosos. El que todo lo quiere para él.

conduerma. Entretenimiento.

condumio. Montón, cantidad grande.

cotia. La carabela de la tierra cuando se endurece superficialmente por efecto de una lluvia que cale poco.- La suciedad de la lengua en las personas enfermas.

embate. Viento flojo, que lleva sólo el tamo al aventar el grano en las eras.

enclente. De mirada fija: Fulano está enclente, fijo, sin cambiar la vista pa ningún lao.

enganío. El que no parte, no se aumenta nada: animal o persona.

entrijo. La grasa donde están pegadas las tripas menudas de los cerdos. Sólo los cochinos tienen entrijo.

entruso. Intruso.

espequero o asadero. Asador de la carne.

espequiar. Buscar camorra; incitar tocando.

galibotes. Piernas largas y grandes: Aquél sí tiene buenos galibotes (= piernas largas).- En sing., palo grande y largo: Fulano trajo un galibote de un palo.

jamponera. Falda alta y ancha.

marmaruta. Se dice más comúnmente malmaruta.

mejedero. Es más corriente y casi exclusivo en Garafía por remejedero. nublina. Neblina.

ñáñaras. Raíz de helecho delgada y seca que no sirva ni para bollo ni para los cerdos: No trajo sino ñánaras de helecho que no sirven pa nada.

ñaspar. Arrebatar.

pancada. Golpe dado con la azada en el terreno.

pecuña. Cosecha muy pequeña, especialmente de cereales.

perenquén. Cualquier cosa colgante de poco valor.

pincora. En Garafía es la única forma usual por pingora.

polvillo. Tierra suelta, en oposición al salón, que es tierra pegajosa.

prepinco (de). Sin irse para ningún lado.

provocación. Náusea.

putiga. Es más frecuente entre la gente que pútiga.

ramal. Cada uno de los lienzos de una pieza: manta, enaguas, etc. 
redaño. El sebo o grasa que cubre el payo grande de todos los animales. rejertero. En Garafía es forma exclusiva para rejartero. rumba. Montón.

salseriar. Lo mismo que churumisgar.

salsero. Lluvia menuda.

sarabio, bia. Zapatudo, cuéscaro: Así están los pajones y los cardos en los días de mucho calor.

sarnar. Cortar la cáscara del tronco de un árbol en redondo para que, al no circular la savia, se pierda.

surrumaque. La suciedad que suelta la ropa muy sucia al lavarla.

teneque. Trozo de alguna cosa-carne, queso, piedra-grande.

\section{BIBLIOGRAFÍA CITADA}

Alvar, M. (1959): El español hablado en Tenerife. Revista de Filología Española, Anejo LXIX.

- (1975-1978): Atlas Lingüístico y Etnográfico de las Islas Canarias (3 vols.). Las Palmas de Gran Canaria, Cabildo Insular.

Álvarez RiXo, J.A. (1992): Voces, frases y proverbios provinciales de nuestras Islas Canarias con sus derivaciones, significados y aplicaciones. C. Díaz Alayón y F.J. Castillo (eds.). La Laguna, Instituto de Estudios Canarios.

DíAz Alayón, C. (1987): Materiales toponímicos de La Palma. La Palma, Cabildo Insular.

- (1990): "Notas de dialectología canaria: el léxico palmero», Revista de Filología (Universidad de La Laguna), 8-9, págs. 127-144.

— (2001): «El léxico de La Palma: materiales y aportaciones anteriores a 1940», Estudios Canarios, XLV, págs. 393-417.

— (2003): «El léxico de La Palma: estudios, materiales y aportaciones del periodo 1940-1970», Estudios sobre el español de Canarias. Vol. 2. Islas Canarias, Academia Canaria de la Lengua, págs. 543-568.

- (2019): «En torno al léxico del español de Canarias. Notas sobre el Vocabulario palmero de Antonino Pestana». En Cazorla Vivas, M.C. et al. (eds.): Lo que hablan las palabras. Estudios de Lexicología, Lexicografía y Gramática en honor a Manuel Alvar Ezquerra. Lugo, Axac, págs. 149-160.

Díaz Alayón, C. y CASTillo, F.J. (1997): «Dominik Josef Wölfel en La Palma», Estudios Canarios, XLI, págs. 129-147. 
- (2006): «Sobre Álvarez Rixo, Lemos Smalley y la etnografía insular», Revista de Estudios Generales de la Isla de La Palma, 2, págs. 565-605.

- (2008): Los estudios históricos y lingüísticos de Dominik Josef Wölfel. Santa Cruz de Tenerife, Ediciones Idea.

- (2013-2014): «Estudio de la lista de voces prehispánicas de Juan Bautista Lorenzo Rodríguez», Almogaren, 44-45, págs. 7-56.

FigUEIREDO, C. de (1945-1947): Grande dicionário da língua portugueza (2 vols.). Lisboa, Livraria Bertrand (14. ${ }^{\mathrm{a}}$ ed.).

FRANCHY y RocA, J. (1908): «Cómo se habla en Canarias», Las Canarias y nuestras posesiones africanas, 760 (año VIII).

HERnándeZ DE LAS CASAS, J.M. (1946): [ Voces de La Palma]. Manuscrito mecanografiado realizado por Max Steffen. Biblioteca Universitaria de La Laguna, ms. 126.

Lugo, S. de (1946): Colección de voces y frases provinciales de Canarias. J. Pérez Vidal (ed.). La Laguna, Universidad de La Laguna.

Millares Cubas, A. (s.a. [1932]): Cómo hablan los canarios. Las Palmas de Gran Canaria.

Pérez García, J. (2009): Fastos biográficos de La Palma. Santa Cruz de La Palma, Sociedad Cosmológica-Caja Canarias.

PÉREZ VIDAL, J. (1963): «La ganadería canaria. Notas histórico-etnográficas», Anuario de Estudios Atlánticos, 9, págs. 237-286.

- (1991): Los portugueses en Canarias. Portuguesismos. Las Palmas de Gran Canaria, Cabildo Insular.

Pestana Rodríguez, A. (1947): Vocabulario palmero. Manuscrito mecanografiado realizado por Max Steffen. Biblioteca Universitaria de La Laguna, ms. 128.

RÉGUlo PÉREZ, J. (1946): «La encuesta lingüístico-folklórica de La Palma», Revista de Historia, XII, págs. 460-466.

- (1947): Reseña de Colección de voces y frases provinciales de Canarias de Sebastián de Lugo, Revista de Historia, XIII, págs. 243-259.

- (1970): Notas acerca del habla de La Palma. La Laguna, Universidad de La Laguna. WöLFEL, D.J. (1965): Monumenta Linguae Canariae. Graz, Akademische DruckVerlagsanstalt.

Carmen DíAZ ALAYÓN Universidad de La Laguna calayon@ull.edu.es 0000-0002-9421-1567 